\title{
Review Article \\ The Importance of the Nurse Cells and Regulatory Cells in the Control of T Lymphocyte Responses
}

\author{
María Guadalupe Reyes García and Fernando García Tamayo \\ Laboratorio de Inmunobiología, Departamento de Biología, Facultad de Química, Universidad Nacional Autónoma \\ de México (UNAM), Ciudad Universitaria, 04510 México, DF, Mexico \\ Correspondence should be addressed to María Guadalupe Reyes García; mgreyes@unam.mx
}

Received 10 August 2012; Accepted 12 October 2012

Academic Editor: Luis I. Terrazas

Copyright (C) 2013 M. G. Reyes García and F. García Tamayo. This is an open access article distributed under the Creative Commons Attribution License, which permits unrestricted use, distribution, and reproduction in any medium, provided the original work is properly cited.

\begin{abstract}
T lymphocytes from the immune system are bone marrow-derived cells whose development and activities are carefully supervised by two sets of accessory cells. In the thymus, the immature young T lymphocytes are engulfed by epithelial "nurse cells" and retained in vacuoles, where most of them (95\%) are negatively selected and removed when they have an incomplete development or express high affinity autoreactive receptors. The mature $\mathrm{T}$ lymphocytes that survive to this selection process leave the thymus and are controlled in the periphery by another subpopulation of accessory cells called "regulatory cells," which reduce any excessive immune response and the risk of collateral injuries to healthy tissues. By different times and procedures, nurse cells and regulatory cells control both the development and the functions of T lymphocyte subpopulations. Disorders in the T lymphocytes development and migration have been observed in some parasitic diseases, which disrupt the thymic microenvironment of nurse cells. In other cases, parasites stimulate rather than depress the functions of regulatory $\mathrm{T}$ cells decreasing $\mathrm{T}$-mediated host damages. This paper is a short review regarding some features of these accessory cells and their main interactions with T immature and mature lymphocytes. The modulatory role that neurotransmitters and hormones play in these interactions is also revised.
\end{abstract}

\section{Background}

Lymphocytes are cells that express receptors that can recognize foreign antigens and activate inflammatory reactions in their surroundings to eliminate them. In this way, lymphocytes provide specific adaptive immunity in all vertebrates. These cells are classified into two main subpopulations, B and $\mathrm{T}$, which recirculate inside the peripheral blood and lymph vessels distributed through the entire body, but lymphocytes can also migrate across the high endothelial cells of venous capillaries and home to different organs where foreign antigens are located. When the lymphocyte's receptors recognize them, the lymphoid cells proliferate and form clones that start a wide set of specific defensive humoral and cellular responses to eliminate microorganisms and infected or malignant cells [1]. In this paper we will refer only to T lymphocytes.

The development of $\mathrm{T}$ lymphocytes in the thymus and the control of their functions in the periphery are mainly controlled by two special cell populations named "nurse cells" and T regulatory cells. Early in their development, immature $\mathrm{T}$ lymphocyte precursors migrate inside the thymus gland and are engulfed by epithelial "thymic nurse cells" (TNCs) [2], which stimulate their development and simultaneously remove most of the defective or self-reactive $\mathrm{T}$ lymphocytes. Once the remaining mature $\mathrm{T}$ cells leave the thymus, they are subjected to a second control by "regulatory cells" that can inhibit their excessive or dangerous responses [3].

The thymic nurse cells eliminate within their vacuoles high affinity autoreactive and poorly developed $\mathrm{T}$ lymphocytes, thus preventing subsequent autoimmune reactions and diseases. The peripheral regulatory cells instead, only reduce the functions of circulating T lymphocytes. While the nursing work kills and negatively selects defective T lymphocytes [4], the regulatory work only suppresses $\mathrm{T}$ lymphocyte-mediated inflammatory reactions, supporting the immune tolerance 
and dampening hypersensitivity responses [5]. The normal modulator activity of nurse cells and regulatory cells can be also disrupted in the course of diverse chronic infectious diseases, particularly those with a parasitic etiology.

1.1. T Lymphocytes Migration. T lymphocyte progenitors enter the thymus via the bloodstream by using integrins, selectins and chemokines during periodically receptive times that are spatially and temporally regulated. Once intrathymic niches are saturated with $\mathrm{T}$ cell progenitors, no other new $\mathrm{T}$ cell progenitors are allowed to enter until the former move on and leave the niches empty [6]. T cell development in the thymus is more active from fetal to perinatal stages and declines with aging [7].

The intrathymic route of immature $\mathrm{T}$ lymphocytes and their eventual development involve an ordered and regulated movement of their progenitors that follow chemokine gradients and interact with adhesion molecules such as integrins, P-selectin, neuropilin-1, and semaphorin-3A [8] through thymic cell networks until they are in the care of nurse cells [9].

Acquiring functional $\mathrm{T}$ cell receptors and coreceptors and recognizing self or non-self antigens are the first decisive steps in the life of immature T lymphocytes in the thymus. In the course of their intrathymic migration, $\mathrm{T}$ lymphocyte precursors engage their bidirectional interactions with TNCs. Initially they are named double negative (DN) cells, since they do not express neither the CD4 nor CD8 coreceptors. The development of these immature lymphocytes consists of four stages (DN1, DN2, DN3, and DN4) according to the expression of the CD4 and CD8 coreceptors [10] on the membrane surface. As the migration goes on, T lymphocytes begin the expression of their receptors to recognize antigens called $\mathrm{T}$ cell receptors (TCR).

In the DN3 stage of their development, immature $\mathrm{T}$ lymphocytes begin the expression of a pre-T cell receptor. Signaling pathways through the intracellular domain of the Notch1 transmembrane protein [11] and others [12] control the recombination and rearrangement of the $\mathrm{V}(\mathrm{D}) \mathrm{J}$ gene segments of the $\alpha, \beta$ or $\gamma, \delta$ chains of these pre-TCRs. Furthermore, the expression of receptors to recognize antigens in immature $\mathrm{T}$ cells is influenced by endogenous cytokines [13], which also modulate the migration of immature lymphocytes through thymic epithelial cells and their subsequent selection.

Once their maturation begins, $\mathrm{T}$ lymphocytes produce interferon gamma (INF- $\gamma$ ), which controls the expression of the fibronectin and laminin receptors on the thymic epithelial cells (TECs), modulates thymocyte adhesion to thymic epithelial cells, induces the expression of the human leukocyte antigen DR in human thymic epithelial cells, and finally is also involved in thymocyte selection and their subsequent release from the TNC vacuoles [14].

Lymphocyte stimulation by TNC promotes the expression of $\mathrm{T}$ cell receptors to recognize antigens and $\mathrm{CD} 4$ and CD8 coreceptors even though lymphocytes have not yet completed their development. Maturing lymphocytes must pass through an intrathymic selective process to avoid apoptosis. Lymphocytes stay alive and leave the thymus only after proving that their receptors do not recognize selfantigens with high affinity. To this purpose, the anatomical integrity of the thymus and the efficient function of their nurse cells to perform the first selective and dangerous event in the life of T lymphocytes are necessary.

Different exogenous molecules including hormones such as oxytocin, neurotensin, insulin growth factor 2 (IGF2), vasopressin [15], glucocorticoids [16], androgens [17], and estrogens [18] and neurotransmitters produced by the autonomic nervous system [19] such as acetylcholine [20], histamine, and serotonin [21] also influence the migration of $\mathrm{T}$ lymphocytes by promoting the expression of adhesive molecules.

1.2. Thymic Involution. The competence of the immune system depends on thymic abilities to support developing $\mathrm{T}$ lymphocytes and eliminate high affinity autoreactive cells. However, thymic activities do not remain constant throughout life. In fact, the size and cellularity of the thymus undergo a physiological decline almost immediately after birth. In adolescence, when the production of sexual hormones increases, thymic involution accelerates and the number of thymocytes gradually decreases at a rate of 3-5\% per year; in adulthood, the number of thymocytes continues its decline at a rate of $1 \%$ per year [22]. Furthermore, transitory increases in the production of steroid hormones reduce thymic cellularity during pregnancy [23], and the thymus reduces both its volume and thymocyte numbers [24] during chronic stress. These changes influence the functions of nurse cells and regulatory cells, thus affecting the number and competence of different $\mathrm{T}$ lymphocyte subpopulations that flow into the peripheral circulation.

Studies on thymus-hormone interactions have shown that thymic involution and T lymphocyte deficiency of aged male rats could be reversed by reducing testosterone levels through surgical castration [25] or by administering the antiestrogenic agent tamoxifen [26]. The elevation in sex hormone levels is associated with the natural involution of the thymus gland since testosterone induces the apoptosis of $\mathrm{CD} 4^{+} \mathrm{CD} 8^{+}$double-positive developing thymocytes [27] via the tumor necrosis factor-alpha (TNF- $\alpha$ ).

Besides, despite the relation between pregnancy and thymic involution [28], other authors [29] have shown that elevated progesterone levels can increase the number and functions of peripheral thymus-derived T cells. Pregnancy and estrogen treatments improve Treg cell functions and enhance the expression of their Forkhead-winged helix box p transcription factor 3 (Foxp3) [30]; other authors [31] have reported similar effects after using glucocorticoids in asthmatic patients. Results suggest that hormones and other factors do not always reduce the T lymphocyte number and functions. Although apoptosis decreases the $\mathrm{T}$ cell activities during aging [32], thymic involution is also associated with an increase in Treg cell numbers in peripheral blood [33, 34]. Other studies have shown that inhibiting Transforming Growth Factor- $\beta$ (TGF- $\beta$ ) signaling in thymic epithelial cells slows thymic involution [35] demonstrating that not only elevated Treg numbers but also increased Treg functions are 
associated with thymic involution. Therefore, physiological or pathological thymic involution affects the development of different T lymphocyte subpopulations at different ages.

On the other hand, the thymus gland and its different cell subpopulations are seriously injured by diverse parasites, which can induce sparse cellular apoptosis, tissue damage, or thymus involution, affecting the development, proliferation, migration, and the export to the periphery of $\mathrm{T}$ lymphocytes, and depressing the cellular immune response. In addition, parasites change the thymic microenvironment by increasing the intrathymic chemokine production and inflammatory cytokines production as well as extracellular matrix components [36].

For instance, in murine Chagas' disease model, the thymus is affected by severe thymocyte depletion mediated by corticosterone and excessive production of TNF- $\alpha$ associated with the export of immature $\mathrm{CD} 4^{+} \mathrm{CD}^{+}$double-positive (DP) cells to the periphery [37]. Similar changes and thymic hypoplasia can be observed in experimental infections of mice with Plasmodium berghei. The parasites cause apoptosis of $\mathrm{CD} 4^{+} \mathrm{CD} 8{ }^{+}$thymocytes, exit of both these DP cells and DN thymocytes to mesenteric lymph nodes, as well as changes in the cortical and medullary limits of the thymus [38].

1.3. Care and Surveillance of Immature T Lymphocytes. Cells specialized in binding to other cells to assist them in their development are called "nurse cells." Several types of cells in the body fit this definition. In particular, skeletal muscle cells in people infected with Trichinella spiralis are a classic example of nurse cells. Infected muscle cells retain the larvae of Trichinella in a cytoplasmic capsule, providing them with a protective envelope and nutrients from the host [39]. Thus, skeletal muscle "nurse cells" protect the Trichinella larvae from recognition, attack, or elimination by immune cells [40].

Some macrophages from the bone marrow also function as "nurse cells" secreting factors that stimulate the growth and development of just formed immature erythrocytes and absorbing their nuclei to enhance their oxygen transport [41]. Other cells with similar nursing functions are the bone marrow-derived fibroblastic stromal cells that infiltrate the synovial tissues of patients with rheumatoid arthritis (RA). Fibroblastic stromal cells contribute to inflammation and bone damage in RA by secreting cytokines and chemokines that trigger both the accumulation and activation of lymphocytes and monocytes in synovium [42]. Mesenchymal stromal cells and bone marrow-derived fibroblastic stromal cells in the synovium also promote antibody production and the survival of B cells, which contribute to synovium damage. Furthermore, Sertoli cells of the testes have been called "nurse cells" because they provide nutrients and growth factors to developing germ cells; therefore, impairment in Sertoli cell differentiation reduces spermatogenesis and testicular size [43].

The best known "nurse cells" are a subpopulation of epithelial cells of the thymus called thymic nurse cells that endocytose newly arrived immature $\mathrm{T}$ lymphocyte progenitors and sequester them in vacuoles named caveoles. Within these vesicles, the intercellular adhesion molecule 1
(ICAM-1) from TNCs interacts with lymphocyte functionassociated antigen 1 (LFA-1) on thymocytes and activates signals necessary for lymphoid cell maturation [44]; other adhesion molecules enhance the selection of self-reactive T lymphocytes. Once these processes are completed, TNCs allow mature $\mathrm{T}$ lymphocytes to leave their cytoplasmic vacuoles and move into peripheral circulation. Defective thymocytes and autoreactive immature $\mathrm{T}$ lymphocytes that fail positive selection die by apoptosis inside nurse cells and are phagocytized by thymic resident macrophages [45].

Thus, the main function of thymic "nurse cells" seems to support the development and survival of healthy T cells and enhance the elimination of aberrant or damaged T cells. The protective role of TNC contrasts with the Trichinella spiralis nurse cells' deleterious functions, which promote invasive ability and survival of parasites and host's tissue damage.

1.4. Thymic Nurse Cells. Nurse cells of the thymus were discovered in mice thirty years ago [2], but later they had also been isolated from humans, rats, pigs, fish, ewes, frogs and chickens [46]. Nurse cells in the thymus are epithelial cells that temporally bind and internalize immature $\mathrm{T}$ lymphocyte progenitors in specialized vesicles [47] to help in their development, maturation, and selection [48]. Although thymic nurse cells are not easily studied in vitro, nurse cell lines are available by transforming nurse cells with the SV40 virus [49].

Thymic nurse cells are the major epithelial component in the thymus microenvironment and one of the major cell populations involved in monitoring the immature $\mathrm{T}$ lymphocytes' access to antigens that can stimulate or suppress their functions. However, the main function of TNCs is to participate in the positive and negative selection of immature T lymphocytes to tolerate self-antigens and eliminate foreign antigens [50]. Furthermore, the interaction between TNCs and immature $\mathrm{T}$ lymphocytes is necessary for their viability during their triple positive stage of intrathymic development [51].

Thymic nurse cells bind and internalize 50-200 immature $\mathrm{TCR}^{-} \mathrm{CD}^{-} \mathrm{CD}^{-}$thymocytes in specialized cytoplasmic vesicles called caveoles, which are formed from the invaginations of the TNC plasma membrane [52]. A fine and detailed description of the internalization process of immature thymocytes into TNCs had been shown in Hendrix et al. [51].

Nurse cells of the thymus were initially described as multicellular complexes expressing cytokeratin 5 (K5) and/or cytokeratin 8 (K8) in their cytoskeleton [14] with a different location in the thymus. TNCs can express lysosomalspecific molecules and different proteases involved in the peptide/major histocompatibility complex (MHC) molecules-MHC class I and MHC class II-presentation. In human TNCs, laminin 211 has been detected [53], which is essential for the binding of these epithelial cells to immature $\mathrm{T}$ lymphocytes and in releasing $\mathrm{T}$ lymphocytes from the TNC vacuoles. Some TNCs also express the epithelial stem cell phenotype-associated transcription factor Trp-63 [51] 
and are $\mathrm{K} 5+\mathrm{K} 8+$ cells, suggesting that TNCs also possess different stages of development.

TNCs also express gap junctions formed by connexin 43 [54] and several P2Z purinergic receptors [55]. Both proteins are necessary in the communication of TNCs with each other, and in propagating calcium waves between neighboring nurse cells. TNCs secrete the hormone thymulin, which is necessary for the production of the Th1 cytokines interleukin-2 (IL-2) and interferon-gamma (INF- $\gamma$ ) in the thymus; they can also secrete IL-18, which helps in the development of fetal thymic $\mathrm{CD}_{11} \mathrm{~b}^{+}$dendritic cells and is also necessary for the induction of self-tolerance [56].

Furthermore, when TNCs are seeded and cultured on microplates, they produce the $\mathrm{E}_{2}$ and $\mathrm{I}_{2}$ prostaglandins [57] suggesting that TNCs may provide all these and other messages to immature $\mathrm{T}$ lymphocytes at specific developmental stages. Changes in the production of these endogenous and exogenous molecules can affect the balance on the events that modulates thymic microenvironment in which the development of T lymphocytes occurs.

On the other hand, TNCs are controlled by ligands and receptors from the endocrine and the nervous systems, since thymic epithelial cells express receptors for diverse hormones and neurotransmitters. Thymic nurse cells produce somatostatin, serotonin, gastrin [58], and the growth hormone [59] whose expression modulates the proliferation of T lymphocytes and thymic nurse cells and stimulates the secretion of thymic hormones, cytokines, chemokines, and extracellular matrix proteins in the thymic microenvironment, thus increasing thymocyte traffic inside and outside the thymus.

Nurse cells of the thymus also express some components of the cholinergic system [60] and acetylcholine. In vitro studies, using rat thymic epithelial cells [61] have demonstrated that adenosine triphosphate or noradrenaline induces the release of IL-6, a cytokine involved in thymocyte proliferation and differentiation. Besides, primary cultures of human and murine thymic epithelial cells produce thymulin [62] in response to beta-endorphin and leu-enkephalin added to the culture.

1.5. Distribution of Nurse Cells in the Thymus. In the thymus gland, nurse cells are distributed in both the cortical and the medullary zones of thymus lobules. In accordance with their location in the thymus, these populations are known as cortical thymic nurse cells (cTNCs) and medullary thymic nurse cells (mTNCs), respectively. These two TNC types share a common embryonic origin, but they exert different functions [63]. Some nurse cells are found within the corticomedullary interphase and express both $\mathrm{K} 5$ and $\mathrm{K} 8$, however.

cTNCs located in the subcapsular region of the thymus contain cytokeratin 8 in their cytoskeleton and engulf viable, immature, double negative $\left(\mathrm{CD} 4^{-} \mathrm{CD} 8^{-}\right)$thymocytes within TNC vacuoles. These cortex thymic nurse cells contain up to 200 immature thymocytes [64] inside caveoles. The inner membrane of caveoles expresses adhesion molecules called caveolins, intercellular adhesion molecule 1 (ICAM-1) and MHC class I and MHC class II molecules, by which cTNCs actively participate in the positive and negative selection of thymocytes [65]. Nurse cells of the thymus cortex also express several proteases such as cathepsin L, thymus-specific serine protease (TSSP) and the multicatalytic protease complex located in thymoproteosomes; all of them are involved in the positive selection of T lymphocytes after the cTNCs display unique self-antigens loaded onto MHC class I molecules [66].

Within cTNCs caveoles, the immature double-negative T lymphocytes transiently express CD25, the $\alpha$ chain of the IL-2 receptor [67] and begin to express $\mathrm{CD} 4^{+}$and $\mathrm{CD} 8^{+}$ at low levels. Upon the induction of IL-7 and delta-Notch ligands, the $\mathrm{DN} \mathrm{T}$ lymphocytes rearrange first the $\beta$ chain and then the $\alpha$ chain of their TCR genes. Afterwards, they proliferate and maturate to the $\alpha \beta \mathrm{TCR}^{\text {high }}$ double-positive $\mathrm{CD} 4^{+} \mathrm{CD}^{+}$stage [66] via an intermediate $\mathrm{CD} 4^{-} \mathrm{CD} 8^{+}$singlepositive, semimature stage. Thus, results suggest that cTNCs are involved in $\alpha \beta$ T cell receptor-mediated positive selection.

In opposition to cortex thymic nurse cells, medullary thymic nurse cells contain semimature T lymphocytes within their caveoles, whose internal membrane surface expresses cytokeratin 5 (K5), and tissue-specific and tissue-restricted peptides. Peripheral self-antigens gain access to the thymus by both the blood supply and by differentiated dendritic cells that migrate from the periphery to the thymus [68]. Medullary TNCs also express the tissue-restricted antigens, insulin and thyroglobulin, the $\mathrm{XC}$-chemokine ligand 1(XCL1), and the CCL19 and CCL21 chemokines to attract dendritic cells and positive selected thymocytes from the thymic cortex, respectively $[69,70]$. The expression of these self-antigens in TNC is partially regulated by the transcription factor autoimmune regulator (AIRE), which also regulates tolerance in periphery [71].

Intravacuolar interactions of positively selected immature $\mathrm{T}$ lymphocytes with all these tissue-restricted peptides are decisive steps for establishing self-tolerance. For this reason, the main functions of medullary thymic epithelial nurse cells are associated with the negative selection of autoreactive $\mathrm{T}$ lymphocytes and the establishment of a selftolerant T cell repertory.

In addition, medullary thymic epithelial cells that express tissue-specific self-antigens indirectly participate in the generation of natural Tregs [72] with the help of dendritic cells. Simultaneously, mTNCs induce the development of Tregulatory cells to compensate the incomplete presentation of self-antigens in the thymus [73].

1.6. The Positive and Negative Selection of Thymocytes. The selection of thymocytes in the thymus is an MHC-TCRrestricted process associated with the recognition of selfantigens. This process is necessary to complete the maturation of $\mathrm{T}$ lymphocytes (positive selection) or to eliminate autoreactive $\mathrm{T}$ lymphocytes by apoptosis (negative selection). Interactions between cortical thymic nurse cells and semimature $\mathrm{T}$ lymphocytes through the affinities of the $\mathrm{MHC} /$ peptide-TCR $\alpha \beta$ define the further fate of lymphoid cells. Strong affinities with self-antigens trigger the deletion of immature T lymphocytes, minimal affinities lead to death by neglect and intermediate affinities promote positive selection 
by survival and differentiation of $\mathrm{CD} 4^{+} \mathrm{CD} 8^{+}$double-positive thymocytes to either the $\mathrm{CD} 4^{+} \mathrm{CD} 8^{-}$or $\mathrm{CD} 4^{-} \mathrm{CD} 8^{+}$singlepositive linage [74].

In the thymic cortex, semimature $\mathrm{T}$ lymphocytes use their new TCRs to recognize self- and non-self antigens associated with MHC molecules on TNCs or dendritic interdigitating cells. $\mathrm{CD} 4^{+} \mathrm{CD}^{+}$double-positive semimature T lymphocytes inside CTNC that recognize self-antigens with low avidity through their $\alpha \beta \mathrm{T}$ cell receptor (TCR) are positively selected [66], as well as those DP semimature T lymphocytes that produce low intensity activating signals through their TCR [10]. Thus, the main function of cortex TNC appears to support the positive selection of $\mathrm{CD}^{+}$or $\mathrm{CD} 8^{+} \mathrm{T}$ cells [75].

Positive selected $\mathrm{CD}^{+}{ }^{+}$or $\mathrm{CD}^{+}{ }^{\mathrm{T}}$ lymphocytes are viable semimature cells transitorily contained in TNC vacuoles, where they express the Qa2 ${ }^{\text {low }} \mathrm{CD} 62 \mathrm{~L}^{\text {low }} \mathrm{HSA} \mathrm{A}^{\text {high }}$ $\mathrm{CD} 6{ }^{\text {high }} \mathrm{CD} 24^{\text {high }}$ phenotype, which is susceptible to apoptosis [76]. As T lymphocytes differentiate and express the Qa2 ${ }^{\text {high }} \mathrm{CD} 62 \mathrm{~L}^{\text {high }} \mathrm{HSA} \mathrm{A}^{\text {low }} \mathrm{CD} 69^{\text {low }} \mathrm{CD} 24^{\text {low }}$ new phenotype, they are transformed in mature cells refractory to apoptosis and are released from the thymus to start their own immunological functions [10]. In addition, when immature T lymphocytes from TNCs have been cultured, they show a decrease in their Bcl-2 expression [77]. This result suggests that they may be less susceptible to apoptosis because of the protection conferred by TNCs [78].

In the neonatal period, $\mathrm{T}$ lymphocytes positively selected (maybe 2\%-5\%) receive a survival signal, express receptors (CCR7 and CCR9) for CC chemokines and move into the thymic medulla [79], although the CCR7 is not necessary for their emigration from the thymus in adulthood. During their migration into thymus medulla, immature $\mathrm{T}$ lymphocytes acquire a single-positive (SP) phenotype either the $\mathrm{CD}^{-} \mathrm{CD}^{+}$or the $\mathrm{CD} 4^{+} \mathrm{CD} 8^{-}$, both of which are dependent on the recognition of MHC class I or MHC class II molecules by their TCRs [80]. Semimature doublepositive cells are developed by stronger or sustained signals from TCRs through the small GTPase RasGRP1, and the kinase ERK yielding $\mathrm{CD}^{+}$SP thymocytes; meanwhile weaker or transient signals on TCRs produce $\mathrm{CD}^{+} \mathrm{SP}$ thymocytes.

When high affinity TCRs of developing $\mathrm{T}$ lymphocytes recognize self-antigens/self-MHC complex in TNC vacuoles or on sparse thymic dendritic cell surface, they do not leave the TNC caveolae [45] and die by apoptosis inside cortical thymic nurse cells or survive and then leave the thymus but into a state of unresponsiveness or anergy.

In this way, immature $\mathrm{T}$ cells make their first immunological synapses with MHC molecules when they are inside TNC caveoles. The recognition of TNC-derived MHC molecules is a critical event for both the positive and negative selection of immature T lymphocytes upon expression of their $\alpha \beta$ TCR [81]. Antibodies specific for either MHC class I or MHC class II molecules reduce the release of viable $\mathrm{T}$ lymphocytes from TNCs to the culture medium [78], thus suggesting that TNCs rescue immature $\mathrm{T}$ lymphocytes from apoptosis through the TCR-MHC interaction.
1.7. The Kiss of Death. Although TNCs can protect some immature T lymphocytes from apoptosis [77], the lymphoid cells confined within TNC caveoles are killed in most cases. The synapse between the internal membrane of the TNC caveolae and the TCR on the membrane surface of immature $\mathrm{T}$ lymphocytes acts as a kiss of death for autoreactive cells. After the high-affinity TCR-mediated recognition of self-antigens expressed on TNC caveoles, autoreactive thymocytes remain arrested within the nurse cells and are eliminated there by apoptosis. The event is called negative selection.

Thymic epithelial cell-mediated apoptosis needs cell priming, and $98 \%$ of the $\mathrm{CD} 4^{+} \mathrm{CD} 8^{+}$double-positive immature $\mathrm{T}$ lymphocytes undergo apoptosis since they are more sensitive to the BAD, PUMA, and HRK-1 apoptotic sensitizer proteins [82] than are single-positive $\mathrm{CD} 4^{+}$or $\mathrm{CD} 8^{+}$cells. The epithelial thymic cell-mediated apoptosis of doublepositive immature $\mathrm{T}$ lymphocytes is also induced by nitric oxide [83], which synergizes with glucocorticoids and activates cathepsin B and caspase-3, -8 , and -9 [84].

On the other hand, adenosine also induces apoptosis into the thymus. In vitro studies have demonstrated that the apoptosis of mouse autoreactive immature $\mathrm{T}$ lymphocytes requires both high doses of adenosine produced by macrophages and adenosine A2 receptors expressed in immature lymphoid cells. The activation of A2 receptors by adenosine induces a Bcl-2-mediated apoptotic process that needs the proapoptotic protein Bim. In humans, thymocyte apoptosis also involves the $\mathrm{Ca}_{2}{ }^{+}$-dependent induction of the transcription factor Nur77, a member of the steroid/thyroid hormone receptor superfamily [85] that binds to the promoters of the Fas ligand, TNF-related apoptosis-inducing ligand, and NDG-1 and -2 apoptosis-inducer proteins.

Once apoptosis is induced in autoreactive immature $\mathrm{T}$ lymphocytes, the epithelial TNCs recognize them via the scavenger receptor B1, a high-density lipoprotein receptor and a phosphatidylserine receptor and then the thymocytes undergoing apoptosis are retained within TNC caveoles. There, apoptotic cell residues are eliminated by lysosomal enzymes from TNCs [86], resident thymic cortex macrophages, or peripherally-recruited macrophages that arrive at the thymus when thymocyte apoptosis is increased [87]. Electron microscopy images from the cortex of the human thymus have shown that macrophages surround TNCs [88]. Macrophages have also been revealed within the vacuoles of TNCs [89], where macrophages move in and out rapidly. In this way, the physiological elimination of autoreactive thymocytes is performed and prevents the further development of autoimmune diseases.

The fatal kiss between the thymic nurse cells and their protected immature lymphocytes is a physiological event that has critical consequences for the development of selftolerance in the immune system [77]. Self-antigens presented by mTNCs are essential for the negative selection of dangerous autoreactive maturing lymphocytes that must die in the thymic nursery [48]. Immune tolerance for self-antigens can be disrupted by defective elimination of autoreactive thymocytes that have a deficient expression of the proapoptotic protein Bim [90], mutations on the tyrosine kinase ZAP-70 
signaling [91] or the depressed expression of the Mer tyrosine kinase [92]. These disorders have been associated with the deficient elimination of autoreactive cells by negative selection [47] resulting in the induction of autoimmune diseases.

The negative selection of autoreactive lymphocytes does fail however, since the deletion of these defective cells is incomplete, and some autoreactive $\mathrm{T}$ lymphocytes evade the kiss of death in the TNC microenvironment [93] and move into the peripheral blood circulation. In general, these autoreactive cells do not induce autoimmune diseases cause they are controlled by $\mathrm{T}$ regulatory (Treg) cells, which suppress peripheral $\mathrm{T}$ lymphocyte-mediated responses against self-antigens [94]. Nevertheless, the loss of the homeostasis between TNC and Treg cell functions can result in the excessive output of autoreactive T lymphocytes or defects in the suppression of $\mathrm{T}$ cells reactivity.

1.8. The Regulatory T Cells. Once T lymphocytes mature and leave the thymus, their surveillance and defensive functions begin to be controlled by other accessory cells called regulatory T (Treg) lymphocytes. The natural Treg cells are thymusderived $\mathrm{T}$ lymphocytes, which modulate many aspects of the normal immune responses, suppressing inflammation, hypersensitivity, or autoimmune mechanisms. However, not all Treg cells develop in the thymus gland [95].

Moreover, not all $\mathrm{T}$ regulatory cells exert a suppressor role since Tregs subpopulations with a proinflammatory function have been reported [96]. Tregs are specifically activated by antigens although their effector function is antigen nonspecific [97]. Besides, the self or non-self antigen binding specificity of the Treg lymphocyte through their TCR does not influence their selective process within the thymus gland when immature Treg cells are under the influence of cytokines, hormones, and neurotransmitters. In addition, Treg lymphocytes exert their suppressive functions on other immune cells [98] by releasing cytokines, through cell-cell contact, or by inducing cytotoxicity or anergy in antigen presenting cells [99].

Treg cells developed in the thymus are referred to as "natural" Treg (nTreg) cells, whereas "adaptive" or "induced" Treg (iTreg) cells are either naïve peripheral Foxp $3^{-} \mathrm{CD} 4^{+} \mathrm{T}$ lymphocytes or Foxp $3^{-} \mathrm{CD}^{+} \mathrm{T}$ lymphocytes, which develop in the periphery upon subimmunogenic antigen presentation during chronic inflammation or normal homeostasis of the gut after T lymphocytes recognize foreign antigens [100, 101]. The origen and location of Treg cells in the body is depicted in Figure 1.

Natural Treg cells are long-lived cells that comprise a very small subpopulation of thymus-derived $\mathrm{CD} 4^{+} \mathrm{T}$ cells $(5-10 \%)$. They are produced as a result of the high-affinity TCR-self peptide:MHC class II molecule interactions between maturing thymocytes and TNCs requiring also of external stimuli such as IL-2, CD80 and CD86. Natural Tregs constitutively express the alpha chain of the IL-2 receptor (CD25), need TGF- $\beta$ and IL-2 for their maduration and are neither phenotypic nor functionally homogeneous [102]. Natural human Tregs (70\%) express the Helios transcription factor, which regulates both Foxp3 expression and regulatory $\mathrm{T}$ cell activity [103], and possess the Foxp $3^{+} \mathrm{Helios}^{+}$ phenotype. Notwithstanding, Foxp $3^{+}$Helios $^{-}$Tregs can be expanded in vitro into Foxp $3^{+}$Helios $^{+} \mathrm{T}$ regulatory cells by adding a DNA oligonucleotide [87].

On the other hand, induced Tregs may play an important role in the immune tolerance of foreign antigens such as those derived from commensal bacteria in the intestine [104], and their functions are essential and complementary to the regulatory function of nTregs. Natural or induced $\mathrm{T}$ regulatory cells have different origins and specificities and exert their functions through distinct mechanisms. An excellent review regarding the role of self-reactivity as the decisive factor in Treg development in the thymus has just been published [105].

Other Treg subsets have been proposed, such as the Type 1 regulatory T cells $(\operatorname{Tr} 1)$ and T-helper-3 (Th3) lymphocytes. The former are T cells, which produce TGF- $\beta$ and IL-10 upon antigen exposure and specific tolerogenic conditions, and the latter produces TGF- $\beta$ upon intestinal tolerance [106]. Accordingly, Tregs are stimulated by different agents and possess different properties.

1.9. The Heterogeneity of Treg Cells. The Treg subpopulation contains suppressor and effector/memory cells that also control tumors and pathogens [101]. The same as all T cells, natural $\mathrm{T}$ regulatory cells are long-lived and migrate from the thymus into the periphery and secondary lymph tissues, where they also balance self-tolerance and autoimmunity. Previously, Coutinho et al. [107] have proposed that Tregs are selected in the thymus upon high-affinity recognition of selfligands in cortex thymic epithelial stromal cells.

All Tregs acquire their specific phenotype and functions when they upregulate the expression of Foxp3, which expression requires Signal Transducer and Activator of Transcription-5 (STAT-5) activation driven by IL-2 [108]. However, it is worth keeping in mind that epithelial and other subtype of cells such as cancer cells can also express the Foxp3 protein [109]. Moreover, Treg cells are modulated by cytokines released by cells that express Toll-like receptors such as TLR-2 and TLR-4, as has been reported in patients with atopic dermatitis [110] and hepatoma cell lines [111], in a context that has not yet been fully explored.

In the thymus, Tregs are thymocytes that develop from Foxp $3^{-} \mathrm{CD} 4^{+} \mathrm{CD} 25^{+}$cells and appear more frequently during the transition of the late $\mathrm{CD} 4^{+} \mathrm{CD} 8^{+} \mathrm{DP}$ stage to the final $\mathrm{CD} 4^{+} \mathrm{CD}^{-}$or $\mathrm{CD} 4^{-} \mathrm{CD} 8^{+} \mathrm{SP}$ stage [112]. $\mathrm{T}$ regulatory cells also express the $\mathrm{CD} 45 \mathrm{RB}^{\text {high }}$ or $\mathrm{CD} 45 \mathrm{RB}{ }^{\text {low }}, \mathrm{CD} 8^{+}$ or $\mathrm{CD}_{3} 8^{-}, \mathrm{CD}^{+} 9^{+}$or $\mathrm{CD}^{-} 9^{-}$, and $\mathrm{CD} 62 \mathrm{~L}^{\text {high }}$ or $\mathrm{CD} 62^{\text {low }}$ membrane markers [113]. However, there are $\mathrm{CD} 4^{+} \mathrm{CD} 25^{-} \mathrm{T}$ cells possessing regulatory functions. Other surface markers expressed in Tregs are CD127 $7^{\text {low }}$, HLA-DR, CD103, CD39, Neuropilin-1 (Nrp-1), and Tumor Necrosis Factor receptor family-related members such as the Glucocorticoid-induced TNF receptor (GITR/TNFRSF18), OX-40, and CD137.

The activated $\mathrm{CD} 8^{+} \mathrm{CD} 25^{+}$natural Treg lymphocytes are thymus-derived cells that share phenotypic and functional characteristics of the $\mathrm{CD} 4^{+}$Tregs, since they also express the cytotoxic T lymphocyte-associated antigen 4 (CTLA-4), 


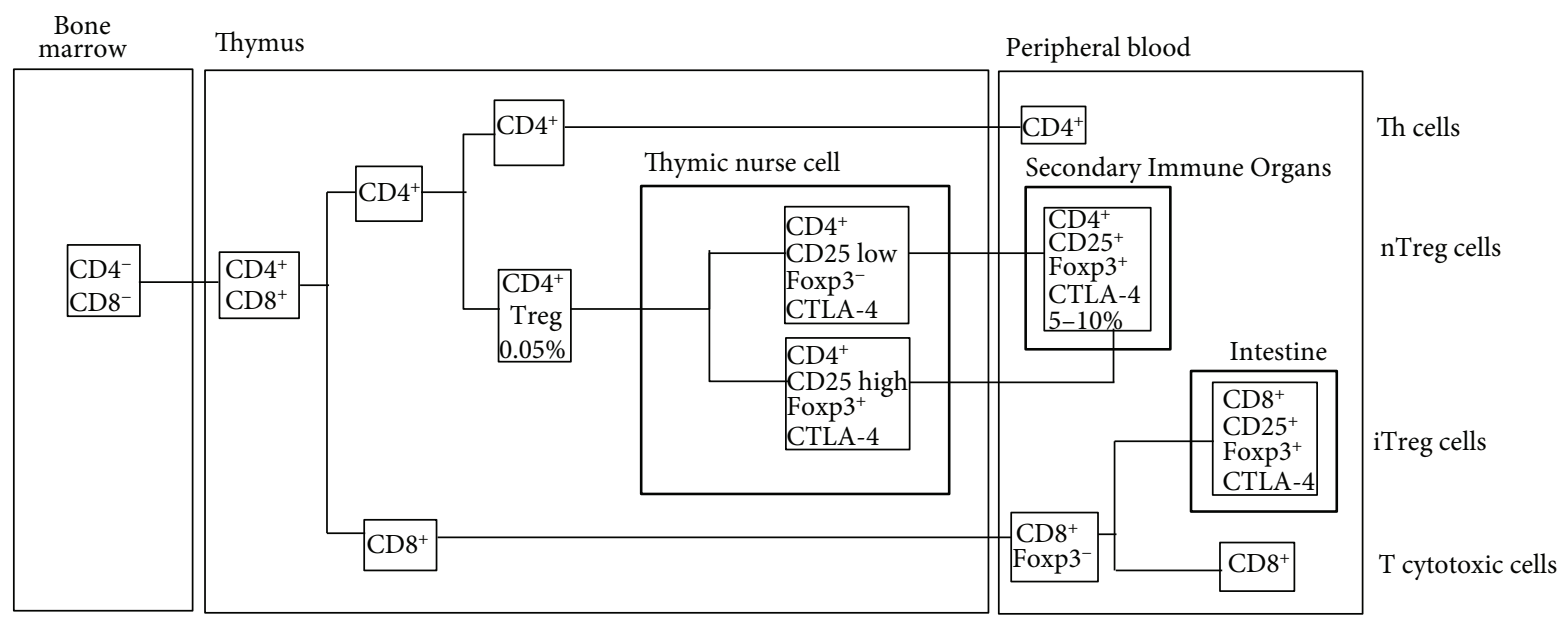

FIgURE 1: The intra- and extrathymic origin of T regulatory (Treg) lymphocytes. The bone marrow-derived pre-T lymphocytes arrive at the thymus microenvironment as double negative $\mathrm{CD} 4^{-} \mathrm{CD} 8^{-}$cells, which are engulfed by thymic nurse cells, where they mature to $\mathrm{CD} 4^{+}$or $\mathrm{CD} 8^{+}$ lymphocytes or are negatively selected. A reduced proportion $(0.05 \%)$ of the $\mathrm{CD} 4^{+}$lymphocytes become regulatory cells by expressing $\mathrm{CD} 25$, Foxp3, CTLA-4, and other molecules. When this subpopulation of natural T regulatory (nTreg) lymphocytes is mature, they are released from the medullary thymic nurse cells, leave the thymus, and go into the blood and peripheral lymphoid organs where they release IL-10 and TGF- $\beta$ suppressor cytokines that downmodulate the functions of other cells from the immune system. A different subpopulation of T regulatory cells can be experimentally induced from $\mathrm{CD}^{+}$cytotoxic lymphocytes located outside the thymus. These lymphocytes exert an in vitro suppressor activity through IL-10, IL-4 , and TGF- $\beta$; they are called inducible T regulatory (iTreg) lymphocytes and have been found as infiltrating cells with an effective antitumor activity.

the Glucocorticoid-induced Tumor Necrosis Factor receptor (GIRT), and the Transforming Growth Factor- $\beta 1[98,114]$. They comprise less than $1 \%$ of $\mathrm{CD} 8^{+}$lymphocytes.

In addition, diverse $\mathrm{CD}^{+}$Tregs subtypes exists, which are naturally produced or induced with cytokines such as IL-4, IL-10, Granulocyte-Macrophage Colony-Stimulating Factor (GM-CSF), IL-2, INF- $\gamma$ and TGF- $\beta$, viral antigens, xenogeneic antigen presenting cells, allogeneic stimulation, non-antigen specific stimulation, cocultures with monocytes, cocultures with LPS-stimulated dendritic cells (DCs), and plasmacytoid DC from tumor ascites [98] among others.

Surprisingly, a fraction (10-15\%) of CD25 ${ }^{+}$natural Treg cells never express or lose the transcription factor Foxp $3^{+}$ when they proliferate in a T cell deficient environment [108]. Some of these Treg-derived Foxp $3^{-} \mathrm{T}$ cells exert an effector $\mathrm{T}$ helper function while others maintain their ability of expressing Foxp3 upon activation [115], showing that T regulatory cells possess plasticity. The Foxp $3^{+} \mathrm{T}$ regulatory cells can also functionally differentiate to control the $\mathrm{T}_{\mathrm{H}} 1, \mathrm{~T}_{\mathrm{H}} 2$, and $\mathrm{T}_{\mathrm{H}} 17$ cell response [116] by changing the expression of the $\mathrm{T}_{H}$ lineage-specific transcription factors T-bet, Interferon Regulatory Factor 4 (IRF-4), and Orphan Nuclear Receptor $\gamma \mathrm{t}(\mathrm{ROR} \gamma \mathrm{t})$, respectively.

Different cells and molecules are involved in the Treg development in the thymus. Accordingly, $\mathrm{T}$ cell expression and signaling, the expression and signaling of CD11a/CD18, CD28, and CD40L on thymocytes, ICAM-1 and CD80, CD86, and CD40 expressed on thymic stromal cells [3] control Tregs development and the selection of their heterogeneous subpopulations [105]. The expression of MHC class II molecules on medullary TEC also promotes Treg development [75]. Tregs develop if the MHC-TCR affinity is high [111], although the affinity for the development of the $\mathrm{CD} 4{ }^{+} \mathrm{CD} 25^{+}$thymocytes is different from that of $\mathrm{CD} 4^{+} \mathrm{CD} 25^{-}$thymocytes. Dendritic cells induce the differentiation of T regulatory cells [117]. TGF- $\beta$ is needed for the Foxp3 expression in Treg cells [108], and glucocorticoids stimulate Treg activity [118]. Tregs need B-lymphocytes to survive and proliferate on the periphery [113]. In addition, IL-2, IL-7, and IL-15 are required for the peripheral maintenance of Tregs, and they are also probably needed for the survival of immature Tregs in the thymus medulla [112].

1.10. Blood Levels and Functions of the Treg Cells. Once Treg cells have been developed, their numbers can be increased or decreased by diverse diseases or physiological conditions, which can influence their suppressor functions according to the quality of the required immune response. In addition, the number and functions of Tregs cells are necessary in controlling autoimmunity since depletion of $\mathrm{CD} 4^{+} \mathrm{CD} 25^{+} \mathrm{T}$ cells in mice, mutations in the Foxp3 gene, or environmental agents affecting Treg cells cause or predispose to autoimmunity [116] because the lack in balancing the activity of self-reactive $\mathrm{T}$ cells produced in the thymus. Thus, $\mathrm{CD} 4^{+}$ Tregs or $\mathrm{CD}^{+}$Tregs appear impaired in number and/or function in diverse autoimmune diseases [98] such as lupus erythematous, autoimmune diabetes, rheumatoid arthritis, myasthenia gravis, multiple sclerosis, allergy, inflammatory bowel disease, hepatitis C, herpes simplex, HIV infections, and cancer. However, Treg lymphocytes are frequently expanded in physiological conditions such as aging [119] and pregnancy [120]. An overview regarding the role of the Treg cells in controling infection, inflammation and the function of other T lymphocytes are depicted in Figure 2. 


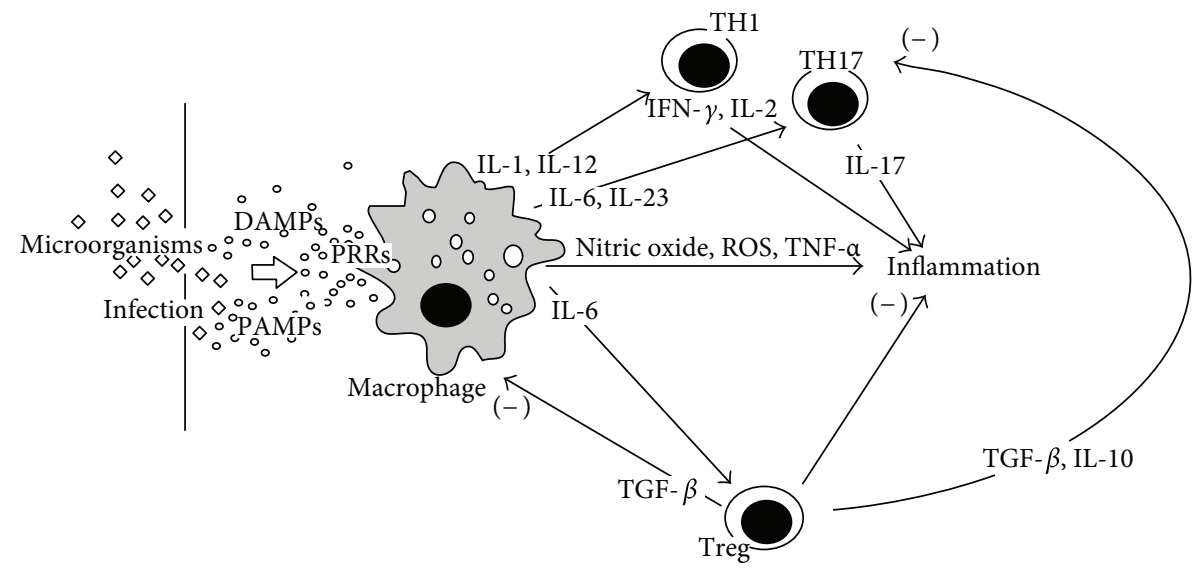

FIGURE 2: A defensive inflammatory response starts after the pattern recognition receptors (PRRs) of macrophages and dendritic cells are stimulated by both pathogen-associated molecular patterns (PAMPs) released by microorganisms and damage-associated molecular patterns (DAMPs) from injured tissues. As a consequence, diverse signaling pathways increase both the production of proinflammatory cytokines and the release of free radicals during the cellular respiratory burst. The evolution of the inflammatory response is modulated by various subpopulations of cells including T lymphocytes. The proinflammatory T lymphocytes (Th1 and Th17) mainly release IL-2, IL-17, and IFN- $\gamma$, and the antiinflammatory lymphocytes (Treg) release TGF- $\beta$ and IL-10. The effective modulatory work of Treg cells gradually slows down the progression of the inflammatory responses and reduces any possible risk of autoimmunity, allergies, or other chronic diseases.

Experimental models of parasitic infection with Strongyloides ratti [121] and Trichuris muris [122] increase the number of Foxp $3^{+}$Treg lymphocytes suppressing the protective immune response and probably reducing the parasiteinduced damage in the host. Similar results have been observed during experimental acute or chronic malaria infection by Plasmodium chabaudi in C57BL/6 mice [123] and in filaria-infected non-obese diabetic mice [124].

Other different studies have shown that there is also an inverse relationship between the peripheral nonphysiological increase in Treg numbers and thymic involution [33]. The numbers of Treg cells in the blood increases as a consequence of thymic involution and lymphopenia, as can be observed in children with the Down syndrome [125]. In opposition, low numbers of circulating Treg cells have been associated with the onset of allergic and autoimmune responses [126]. Other authors have reported that the proportion of Treg cells increases in the spleen and lymph nodes of mice with experimentally induced arthritis [127].

Although deficient $\mathrm{T}$ lymphocyte-mediated immune responses are usually associated with elevated amounts of Treg cells in the blood, the increased production of proinflammatory cytokines such as IL-17 and IL-18 and the elevated number of Th17 lymphocytes are frequently associated to decreased numbers of Treg lymphocytes in the blood and lymphoid organs [128].

In support of the role for Treg cells in the prevention of immunopathology, it has been reported that the experimental depletion of Foxp $3^{+}$Treg cells reduces the control of the inflammatory immune responses, increases the frequency of autoimmune reactions due to TCR-mediated self-antigen recognition and enhances the development of a scurfy-like disease in mice, which die at 3-4 weeks of age [129]. In contrast, Foxp $3^{+}$Treg cells from mice deficient in
CD5, a negative regulator of TCR signaling increases the suppressive activity of their Treg cells [97].

Furthermore, the presence of cellular markers of Treg cells in the microenvironment of thymic nurse cells [71] suggests a relationship between autoimmunity and disorders in the intra-TNC maturation of Treg cells. Incomplete Treg cell development in TNCs can result in defective Treg cell suppressor activity and consequently in the development of autoimmune reactions or diseases. For example, nonobese diabetic (NOD) mice are diabetic because of a defect in their antigen presenting cells to activate Treg cells. NOD mice also have Treg cells, which are defective in their regulatory function and possess lower percentages of $\mathrm{CD} 4^{+} \mathrm{CD} 25^{+} \mathrm{T}$ regulatory cells than NOD mice that never develop diabetes [130].

The extremely complex relationship between Treg cells and autoimmunity is a function not only of the defective suppressor activities of peripheral Treg cells, however. Neurotransmitters and sex hormones have recently been added to the long list of modulators of the Treg cell function. Thus, in vitro experiments show that pituitary adenylyl cyclase-activating polypeptide (PACAP) [131], vasoactive intestinal peptide [132], and nicotine [133] increase the suppressor activity of Treg cells. Furthermore, studies of cultured fluorescence-activated-sorted Tregs from pregnant women and peripheral blood mononuclear cells from nonpregnant women have revealed that progesterone and 17 $\beta$-estradiol especially decrease the expression of Foxp3 in $\mathrm{CD} 4{ }^{\mathrm{dim}} \mathrm{CD} 25^{\text {high }}$ Treg cells [134] as well as their cell numbers, although these Tregs cells maintain their regulatory function. In contrast, other authors have shown that oestrogen enhances the frequency of Treg cells and reduce the production of IL-17 in a mouse model of multiple sclerosis [135]. 
The suppressive control of $\mathrm{T}$ lymphocyte responses is a complex event in which the major inductors are Treg cells modulated by numerous factors coming from the immune system or not.

1.11. Regulating the Regulators. Since immune system responses are regulated by Treg cells and MHC class IIexpressing nurse epithelial cells from the thymus regulate the development of Treg cells $[75,136]$, a question arises: what regulates both the development and the functions of thymic nurse cells? To answer this question, most researchers have focused their attention outside the thymus gland, specifically on the endocrine [137] and the nervous [138, 139] systems.

Understanding the interactions between the nervous and immune systems has considerably increased [140] in the last three decades, and a great deal of studies have shown that these interactions are possible because immune and nervous cells share receptors for several neurotransmitters and cytokines [139]. Moreover, the innervation of the thymus gland, bone marrow and all secondary organs of the immune system by the autonomous nervous system are essential for the functioning of the immune system [140].

Accordingly, the connective tissue of the thymus contains non-myelinated nerves forming a lattice over their surface [141]. These nerves contain calcitonin gene-related peptide (CGRP), noradrenaline, substance P (SP), vasointestinal peptide (VIP), and neuropeptide Y (NPY) [142-148]; other nerves have acetylcholinesterase, which can affect the thymocyte development. The direct effect of GABA, Histamine, NPY, SP, VIP, and CGRP on the proliferation of rat thymic epithelial cells was reported years ago [149]. The P2Z receptors, a kind of purinergic receptor, were later demonstrated to exist in thymic epithelial nurse cells [150]. In addition, catecholamines (adrenaline, noradrenaline, and dopamine) from the sympathetic nervous system have a main role in controlling lymphocyte development and immunomodulation [151].

Since the thymus is innervated by the sympathetic nervous system through norepinephrine [141], sympathectomy of adult rats results in a reduction of thymus weight, decreased intrathymic cellularity and increased T cell apoptosis [143] by affecting noradrenergic, vasointestinal peptide, acetylcholine and CGRP nervous fibers in the thymus. In contrast, other authors [144] have shown that the peripheral administration of 6-hydroxydopamine (6-OHDA) increased the numbers of $\mathrm{CD} 4^{+}$Foxp $3^{+}$Tregs in the spleen and lymph nodes in a TGF- $\beta$-dependent manner without affecting their regulatory function or the frequency of all $\mathrm{CD} 4^{+}$and $\mathrm{CD} 8^{+}$ T cells.

On the other hand, in vitro experiments have confirmed that cultured thymic epithelial cells express both the $\alpha$, $\beta$, and $\varepsilon$ subunits of the acetylcholine receptor similar to those shown in muscle cells [20] and functional $\beta 1$ and $\beta 2$ mRNA to express adrenoreceptors, activated by adrenaline and noradrenaline [143]. Besides, the adrenergic agonist carbachol inhibits apoptosis of DP thymocytes by TECs [146]. Furthermore, immunohistochemistry assays have shown that epithelial cells of the rat thymus are close to catecholaminergic nerves controlled by dopamine [147].

A possible role for acetylcholine has been also proposed in the mutual interplay between immature lymphocytes and thymic epithelial cells because the TE750 thymic epithelial cell line and primary thymic epithelial cell cultures have shown in vitro the expression of acetylcholine, the $\alpha 3, \alpha 5$, and $\beta 4$ mRNA subunits of one cholinergic receptor and choline acetyltransferase [60]. Outside the thymus gland, the histamine released by bone marrow-derived mast cells inhibits the in vitro suppressor function of Treg lymphocytes and downregulate the expression of CD25 and Foxp3 markers of $\mathrm{CD} 4^{+} \mathrm{CD} 25^{+}$cells [152] via the histamine 1 receptor expressed by these cells.

Other studies have revealed that the levels of the inhibitory neurotransmitter gamma-aminobutyric acid (GABA) are elevated in the thymus during the immune response [153] as compared with other glands. Epithelial cells in thymic medulla expresses the glutamate decarboxylase- 67 isoform, which predominantly synthesizes GABA in the central nervous system [154], and the thymus also expresses high GABA-transaminase activity after IL-1 stimulation [155]. Nevertheless, the expression of components of the GABAergic system or GABA receptor subunits has not been demonstrated in thymic epithelial cells. We have found evidence for a GABAergic system in mouse peritoneal macrophages [156], but the presence of a similar system in intrathymic macrophages has not been addressed.

Regarding the role of GABA on the thymus and lymphocytes, Tyurenkov et al. [157] demonstrated that baclofen, a GABA-B receptor agonist, restores thymus weight and thymocyte numbers after experimental immunosuppression. Notwithstanding its inhibitory effect on the cells from the nervous system, GABA increases the proliferation of rat thymic epithelial cells cultured in vitro [149], whilst its oral administration inhibits both diabetes development in type 2 diabetic mice [158] and inflammation in fat dietfed mice [159] by increasing the frequency of their Tregs cells. These two later in vivo results suggest that GABA administration may be a useful tool that enhance the effects of the conventional therapy for preventing type 1 diabetes and other $\mathrm{T}$ lymphocyte-mediate autoimmune diseases in mice, although the role of GABA in the TNC-Treg cells interaction remains unexplored.

Thymic nurse cells are the main engaged cells in the development and selection of immature $\mathrm{T}$ lymphocyte in the thymus. Although relationships between TNCs and the nervous system have been emerging in the last decades, their data are scanty. Even more limited are the studies regarding the relationships between neurotransmitters or neuropeptides and the density of their receptors expressed on immune cell subsets [160]. Further studies are needed to unveil the existing interactions between the nervous system and both TNC and Tregs cells completely. Understanding the mechanisms by which the vegetative nervous system regulate the TNC functions and development through neurotransmitters and neuropeptides may be helpful in controlling autoimmune diseases, transplants, inflammation, and allergy. 


\section{Acknowledgment}

This study was supported by Grant IN-211311 from the Dirección General de Apoyo al Personal Académico (DGAPA) of the Universidad Nacional Autónoma de México. The authors would like to thank Mr. Joseph Doshner Maute for correcting the English version of the manuscript.

\section{References}

[1] E. V. Rothenberg, "T cell lineage commitment: Identity and renunciation," Journal of Immunology, vol. 186, no. 12, pp. 6649-6655, 2011.

[2] H. Wekerle, U. P. Ketelsen, and M. Ernst, "Thymic nurse cells. Lymphoepithelial cell complexes in murine thymuses: morphological and serological characterization," Journal of Experimental Medicine, vol. 151, no. 4, pp. 925-944, 1980.

[3] S. Sakaguchi, "Naturally arising Foxp3-expressing CD25+ CD4+ regulatory T cells in immunological tolerance to self and non-self," Nature Immunology, vol. 6, no. 4, pp. 345-352, 2005.

[4] L. K. Aguilar, E. Aguilar-Cordova, J. Cartwright Jr., and J. W. Belmont, "Thymic nurse cells are sites of thymocyte apoptosis," Journal of Immunology, vol. 152, no. 6, pp. 2645-2651, 1994.

[5] L. F. Lu and A. Rudensky, "Molecular orchestration of differentiation and function of regulatory T cells," Genes and Development, vol. 23, no. 11, pp. 1270-1282, 2009.

[6] S. E. Prockop and H. T. Petrie, "Regulation of thymus size by competition for stromal niches among early T cell progenitors," Journal of Immunology, vol. 173, no. 3, pp. 1604-1611, 2004.

[7] D. Aw and D. B. Palmer, "The origin and implication of thymic involution," Aging and Disease, vol. 2, no. 5, pp. 437-443, 2011.

[8] Y. Lepelletier, S. Smaniotto, R. Hadj-Slimane et al., "Control of human thymocyte migration by neuropilin-1/semaphorin-3Amediated interactions," Proceedings of the National Academy of Sciences of the United States of America, vol. 104, no. 13, pp. 5545-5550, 2007.

[9] E. Ladi, X. Yin, T. Chtanova, and E. A. Robey, "Thymic microenvironments for $\mathrm{T}$ cell differentiation and selection," Nature Immunology, vol. 7, no. 4, pp. 338-343, 2006.

[10] P. E. Love and A. Bhandoola, "Signal integration and crosstalk during thymocyte migration and emigration," Nature Reviews Immunology, vol. 11, no. 7, pp. 469-477, 2011.

[11] J. B. Tan, I. Visan, J. S. Yuan, and C. J. Guidos, "Requirement for Notch1 signals at sequential early stages of intrathymic T cell development," Nature Immunology, vol. 6, no. 7, pp. 671-679, 2005.

[12] L. Miosge and R. Zamoyska, "Signalling in T-cell development: is it all location, location, location?" Current Opinion in Immunology, vol. 19, no. 2, pp. 194-199, 2007.

[13] A. A. Yarilin and I. M. Belyakov, "Cytokines in the thymus: production and biological effects," Current Medicinal Chemistry, vol. 11, no. 4, pp. 447-464, 2004.

[14] J. M. Lagrota-Cândido, D. M. S. Villa-Verde, F. H. Vanderlei Jr., and W. Savino, "Extracellular matrix components of the mouse thymus microenvironment. V. Interferon- $\gamma$ modulates thymic epithelial cell/thymocyte interactions via extracellular matrix ligands and receptors," Cellular Immunology, vol. 170, no. 2, pp. 235-244, 1996.

[15] V. Geenen, “Thymus-dependent T cell tolerance of neuroendocrine functions: principles, reflections, and implications for tolerogenic/negative self-vaccination," Annals of the New York Academy of Sciences, vol. 1088, pp. 284-296, 2006.

[16] E. Roggero, A. R. Pérez, M. Tamae-Kakazu et al., "Edogenous glucocorticoids cause thymus atrophy but are protective during acute Trypanosoma cruzi infection," Journal of Endocrinology, vol. 190, no. 2, pp. 495-503, 2006.

[17] N. J. Olsen, G. Olson, S. M. Viselli, X. Gu, and W. J. Kovacs, "Androgen receptors in thymic epithelium modulate thymus size and thymocyte development," Endocrinology, vol. 142, no. 3, pp. 1278-1283, 2001.

[18] A. L. Zoller and G. J. Kersh, "Estrogen induces thymic atrophy by eliminating early thymic progenitors and inhibiting proliferation of $\beta$-selected thymocytes," Journal of Immunology, vol. 176, no. 12, pp. 7371-7378, 2006.

[19] K. Bulloch and W. Pomerantz, "Autonomic nervous system innervation of thymic-related lymphoid tissue in wildtype and nude mice," Journal of Comparative Neurology, vol. 228, no. 1, pp. 57-68, 1984.

[20] A. Wakkach, T. Guyon, C. Bruand, S. Tzartos, S. CohenKaminsky, and S. Berrih-Aknin, "Expression of acetylcholine receptor genes in human thymic epithelial cells: implications for myasthenia gravis," Journal of Immunology, vol. 157, no. 8, pp. 3752-3760, 1996.

[21] G. Csaba and P. Kovács, "Perinuclear localization of biogenic amines (serotonin and histamine) in rat immune cells," Cell Biology International, vol. 30, no. 11, pp. 861-865, 2006.

[22] B. Bodey, B. Bodey Jr., S. E. Siegel, and H. E. Kaiser, "Involution of the mammalian thymus, one of the leading regulators of aging," In Vivo, vol. 11, no. 5, pp. 421-440, 1997.

[23] A. L. Zoller, F. J. Schnell, and G. J. Kersh, "Murine pregnancy leads to reduced proliferation of maternal thymocytes and decreased thymic emigration," Immunology, vol. 121, no. 2, pp. 207-215, 2007.

[24] I. Zivković, A. Rakin, D. Petrović-Djergović, B. Miljković, and M. Mićić, "The effects of chronic stress on thymus innervation in the adult rat," Acta Histochemica, vol. 106, no. 6, pp. 449-458, 2005.

[25] M. D. Kendall, F. T. A. Fitzpatrick, B. D. Greenstein, F. Khoylou, B. Safieh, and A. Hamblin, "Reversal of ageing changes in the thymus of rats by chemical or surgical castration," Cell and Tissue Research, vol. 261, no. 3, pp. 555-564, 1990.

[26] P. P. Sfikakis, N. Kostomitsopoulos, C. Kittas et al., "Tamoxifen exerts testosterone-dependent and independent effects on thymic involution," International Journal of Immunopharmacology, vol. 20, no. 6, pp. 305-312, 1998.

[27] J. A. Guevara Patiño, M. W. Marino, V. N. Ivanov, and J. Nikolich-Zugich, "Sex steroids induce apoptosis of CD4+CD8+ double-positive thymocytes via TNF-alpha," European Journal of Immunology, vol. 30, no. 9, pp. 2586-2592, 2000.

[28] T. A. Tibbetts, F. DeMayo, S. Rich, O. M. Conneely, and B. W. O'Malley, "Progesterone receptors in the thymus are required for thymic involution during pregnancy and for normal fertility", Proceedings of the National Academy of Sciences of the United States of America, vol. 96, no. 21, pp. 12021-12026, 1999.

[29] G. Mao, J. Wang, Y. Kang et al., "Progesterone increases systemic and local uterine proportions of CD4 +CD25+ Treg cells during midterm pregnancy in mice," Endocrinology, vol. 151, no. 11, pp. 5477-5488, 2010.

[30] M. J. Polanczyk, C. Hopke, J. Huan, A. A. Vandenbark, and H. Offner, "Enhanced FoxP3 expression and Treg cell function in pregnant and estrogen-treated mice," Journal of Neuroimmunology, vol. 170, no. 1-2, pp. 85-92, 2005. 
[31] C. Karagiannidis, M. Akdis, P. Holopainen et al., "Glucocorticoids upregulate FOXP3 expression and regulatory T cells in asthma," Journal of Allergy and Clinical Immunology, vol. 114, no. 6, pp. 1425-1433, 2004.

[32] S. Gupta, H. Su, R. Bi, S. Agrawal, and S. Gollapudi, "Life and death of lymphocytes: a role in immunesenescence," Immunity and Ageing, vol. 2, article 12, 2005.

[33] B. C. Chiu, V. R. Stolberg, H. Zhang, and S. W. Chensue, "Increased Foxp3+ Treg cell activity reduces dendritic cell costimulatory molecule expression in aged mice," Mechanisms of Ageing and Development, vol. 128, no. 11-12, pp. 618-627, 2007.

[34] R. Simone, A. Zicca, and D. Saverino, "The frequency of regulatory $\mathrm{CD} 3+\mathrm{CD} 8+\mathrm{CD} 28-\mathrm{CD} 25+\mathrm{T}$ lymphocytes in human peripheral blood increases with age," Journal of Leukocyte Biology, vol. 84, no. 6, pp. 1454-1461, 2008.

[35] M. M. Hauri-Hohl, S. Zuklys, M. P. Keller et al., “TGF- $\beta$ signaling in thymic epithelial cells regulates thymic involution and postirradiation reconstitution," Blood, vol. 112, no. 3, pp. 626-634, 2008.

[36] W. Savino, "The thymus is a common target organ in infectious diseases," PLoS Pathogens, vol. 2, no. 6, article e62, 2006.

[37] A. R. Pérez, E. Roggero, A. Nicora et al., "Thymus atrophy during Trypanosoma cruzi infection is caused by an immunoendocrine imbalance," Brain, Behavior, and Immunity, vol. 21, no. 7, pp. 890-900, 2007.

[38] C. Francelin, L. C. Paulino, J. Gameiro, and L. Verinaud, "Effects of Plasmodium berghei on thymus: high levels of apoptosis and premature egress of CD4+CD8+ thymocytes in experimentally infected mice," Immunobiology, vol. 216, no. 10, pp. 1148-1154, 2011.

[39] Z. Wu, L. Sofronic-Milosavljevic, I. Nagano, and Y. Takahashi, "Trichinella spiralis: nurse cell formation with emphasis on analogy to muscle cell repair," Parasites and Vectors, vol. 1, article 27, 2008.

[40] T. Boonmars, Z. Wu, I. Nagano, T. Nakada, and Y. Takahashi, "Differences and similarities of nurse cells in cysts of Trichinella spiralis and T. pseudospiralis," Journal of Helminthology, vol. 78, no. 1, pp. 7-16, 2004.

[41] J. Palis, "Developmental biology: no red cell is an island," Nature, vol. 432, no. 7020, pp. 964-965, 2004.

[42] T. Ochi, H. Yoshikawa, T. Toyosaki-Maeda, and P. E. Lipsky, "Mesenchymal stromal cells. Nurse-like cells reside in the synovial tissue and bone marrow in rheumatoid arthritis," Arthritis Research \& Therapy, vol. 9, no. 1, pp. 201-206, 2007.

[43] C. Petersen and O. Söder, "The Sertoli cell-a hormonal target and 'super' nurse for germ cells that determines testicular size," Hormone Research, vol. 66, no. 4, pp. 153-161, 2006.

[44] U. Cordes, M. Pedersen, L. Bastholm, M. Nielsen, and O. Werdelin, "Murine thymic nurse cells express ICAM-1 on caveolar and vacuolar membranes," Scandinavian Journal of Immunology, vol. 46, no. 4, pp. 344-348, 1997.

[45] J. M. Feng, J. S. Wu, A. T. Campagnoni, and W. F. Chen, "Nonspecific esterase released from thymic macrophages accumulates in the apoptotic thymocytes: an indication for this enzyme participating in the clearance of apoptotic thymocytes," European Journal of Immunology, vol. 32, no. 5, pp. 1386-1392, 2002.

[46] M. Pezzano, M. Samms, M. Martinez, and J. Guyden, "Questionable thymic nurse cell," Microbiology and Molecular Biology Reviews, vol. 65, no. 3, pp. 390-403, 2001.
[47] P. Andrews and R. L. Boyd, "The murine thymic nurse cell: an isolated thymic microenvironment," European Journal of Immunology, vol. 15, no. 1, pp. 36-42, 1985.

[48] J. C. Guyden and M. Pezzano, "Thymic nurse cells: a microenvironment for thymocyte development and selection," International Review of Cytology, vol. 223, pp. 1-37, 2003.

[49] M. Pezzano, Y. Li, Y. M. Yang, and J. Guyden, “The immortalization of thymic nurse cells by SV40 virus," Cellular Immunology, vol. 133, no. 2, pp. 434-445, 1991.

[50] T. Akiyama, Y. Shimo, H. Yanai et al., "The tumor necrosis factor family receptors RANK and CD40 cooperatively establish the thymic medullary microenvironment and self-tolerance," Immunity, vol. 29, no. 3, pp. 423-437, 2008.

[51] T. M. Hendrix, R. V. E. Chilukuri, M. Martinez et al., "Thymic nurse cells exhibit epithelial progenitor phenotype and create unique extra-cytoplasmic membrane space for thymocyte selection," Cellular Immunology, vol. 261, no. 2, pp. 81-92, 2010.

[52] D. Philp, M. Pezzano, Y. Li, C. Omene, W. Boto, and J. Guyden, "The binding, internalization, and release of thymocytes by thymic nurse cells," Cellular Immunology, vol. 148, no. 2, pp. 301-315, 1993.

[53] J. S. Ocampo, J. M. de Brito, E. Corrêa-de-Santana, R. Borojevic, D. M. S. Villa-Verde, and W. Savino, "Laminin-211 controls thymocyte-thymic epithelial cell interactions," Cellular Immunology, vol. 254, no. 1, pp. 1-9, 2008.

[54] L. A. Alves, A. C. C. de Carvalho, E. O. Cirne Lima et al., "Functional gap junctions in thymic epithelial cells are formed by connexin 43," European Journal of Immunology, vol. 25, no. 2, pp. 431-437, 1995.

[55] R. D. Bisaggio, O. K. Nihei, P. M. Persechini, W. Savino, and L. A. Alves, "Characterization of P2 receptors in thymic epithelial cells," Cellular and Molecular Biology, vol. 47, no. 1, pp. 19-31, 2001.

[56] H. Ito, E. Esashi, T. Akiyama, J. I. Inoue, and A. Miyajima, "IL18 produced by thymic epithelial cells induces development of dendritic cells with CD11b in the fetal thymus," International Immunology, vol. 18, no. 8, pp. 1253-1263, 2006.

[57] J. E. McCormack, J. Kappler, P. Marrack, and J. Y. Westcott, "Production of prostaglandin E2 and prostacyclin by thymic nurse cells in culture," Journal of Immunology, vol. 146, no. 1, pp. 239-243, 1991.

[58] I. M. Kvetnoy, V. O. Polyakova, A. V. Trofimov et al., "Hormonal function and proliferative activity of thymic cells in humans: immunocytochemical correlations," Neuroendocrinology Letters, vol. 24, no. 3-4, pp. 263-268, 2003.

[59] W. Savino, "Neuroendocrine control of T cell development in mammals: role of growth hormone in modulating thymocyte migration," Experimental Physiology, vol. 92, no. 5, pp. 813-817, 2007.

[60] M. Mihovilovic and J. Butterworth-Robinette, "Thymic epithelial cell line expresses transcripts encoding $\alpha-3, \alpha-5$ and $\beta$ 4 subunits of acetylcholine receptors, responds to cholinergic agents and expresses choline acetyl transferase. An in vitro system to investigate thymic cholinergic mechanisms," Journal of Neuroimmunology, vol. 117, no. 1-2, pp. 58-67, 2001.

[61] B. Von Patay, B. Kurz, and R. Mentlein, "Effect of transmitters and co-transmitters of the sympathetic nervous system on interleukin-6 synthesis in thymic epithelial cells," NeuroImmunoModulation, vol. 6, no. 1-2, pp. 45-50, 1999.

[62] W. Savino, M. C. Gagnerault, J. F. Bach, and M. Dardenne, "Neuroendocrine control of thymic hormonal production. II. 
Stimulatory effects of endogenous opioids on thymulin production by cultured human and murine thymic epithelial cells," Life Sciences, vol. 46, no. 23, pp. 1687-1697, 1990.

[63] S. W. Rossi, A. P. Chidgey, S. M. Parnell et al., "Redefining epithelial progenitor potential in the developing thymus," European Journal of Immunology, vol. 37, no. 9, pp. 2411-2418, 2007.

[64] M. Lahoud, D. Vremec, R. L. Boyd, and K. Shortman, "Characterization of thymic nurse-cell lymphocytes, using an improved procedure for nurse-cell isolation," Developmental Immunology, vol. 3, no. 2, pp. 103-112, 1993.

[65] S. J. Yang, S. Ahn, C. S. Park et al., "The quantitative assessment of MHC II on thymic epithelium: implications in cortical thymocyte development," International Immunology, vol. 18, no. 5, pp. 729-739, 2006.

[66] Y. Takahama, K. Tanaka, and S. Murata, "Modest cortex and promiscuous medulla for thymic repertoire formation," Trends in Immunology, vol. 29, no. 6, pp. 251-255, 2008.

[67] H. T. Petrie, M. Pearse, R. Scollay, and K. Shortman, "Development of immature thymocytes: initiation of CD3, CD4, and CD8 acquisition parallels down-regulation of the interleukin 2 receptor $\alpha$ chain," European Journal of Immunology, vol. 20, no. 12, pp. 2813-2815, 1990.

[68] R. Bonasio, M. L. Scimone, P. Schaerli, N. Grabie, A. H. Lichtman, and U. H. von Andrian, "Clonal deletion of thymocytes by circulating dendritic cells homing to the thymus," Nature Immunology, vol. 7, no. 10, pp. 1092-1100, 2006.

[69] T. Nitta, S. Murata, T. Ueno, K. Tanaka, and Y. Takahama, "Thymic microenvironments for T-cell repertory formation," Advances in Immunology, vol. 99, pp. 59-94, 2008.

[70] Y. Lei, A. M. Ripen, N. Ishimaru et al., "Aire-dependent production of XCL1 mediates medullary accumulation of thymic dendritic cells and contributes to regulatory $\mathrm{T}$ cell development," Journal of Experimental Medicine, vol. 208, no. 2, pp. 383-394, 2011.

[71] I. Hansenne, C. Louis, H. Martens et al., "Aire and Foxp3 expression in a particular microenvironment for T cell differentiation," NeuroImmunoModulation, vol. 16, no. 1, pp. 35-44, 2009.

[72] K. Aschenbrenner, L. M. D’Cruz, E. H. Vollmann et al., "Selection of Foxp3+ regulatory T cells specific for self antigen expressed and presented by Aire+ medullary thymic epithelial cells," Nature Immunology, vol. 8, no. 4, pp. 351-358, 2007.

[73] E. Román, H. Shino, F. X. F. Qin, and Y. J. Liu, "Cutting edge: hematopoietic-derived APCs select regulatory T cells in thymus," Journal of Immunology, vol. 185, no. 7, pp. 3819-3823, 2010.

[74] S. Guerder, C. Viret, H. Luche, L. Ardouin, and B. Malissen, "Differential processing of self-antigens by subsets of thymic stromal cells," Current Opinion in Immunology, vol. 24, no. 1, pp. 99-104, 2012.

[75] S. J. Bensinger, A. Bandeira, M. S. Jordan, A. J. Caton, and T. M. Laufer, "Major histocompatibility complex class II-positive cortical epithelium mediates the selection of CD4+25+immunoregulatory T cells," Journal of Experimental Medicine, vol. 194, no. 4, pp. 427-438, 2001.

[76] M. A. Weinreich and K. A. Hogquist, "Thymic emigration: when and how T cells leave home," Journal of Immunology, vol. 181, no. 4, pp. 2265-2270, 2008.

[77] M. Gatzka and C. M. Walsh, "Apoptotic signal transduction and T cell tolerance," Autoimmunity, vol. 40, no. 6, pp. 442-452, 2007.
[78] M. Pezzano, Y. Li, D. Philp et al., "Thymic nurse cell rescue of early CD4+CD8+ thymocytes from apoptosis," Cellular and Molecular Biology, vol. 41, no. 8, pp. 1099-1111, 1995.

[79] N. Taylor, "CCR7/CCR9: knockin' on the thymus door," Blood, vol. 115, no. 10, pp. 1861-1862, 2010.

[80] J. J. Priatel, X. Chen, S. Dhanji, N. Abraham, and H. S. Teh, "RasGRP1 transmits prodifferentiation TCR signaling that is crucial for CD4 T cell development," Journal of Immunology, vol. 177, no. 3, pp. 1470-1480, 2006.

[81] M. Martinez, M. Samms, T. M. Hendrix, O. Adeosun, M. Pezzano, and J. C. Guyden, "Thymic nurse cell multicellular complexes in HY-TCR transgenic mice demonstrate their association with MHC restriction," Experimental Biology and Medicine, vol. 232, no. 6, pp. 780-788, 2007.

[82] J. A. Ryana, J. K. Brunellea, and A. Letai, "Heightened mitochondrial priming is the basis for apoptotic hypersensitivity of CD4+ CD8+ thymocytes," Proceedings of the National Academy of Sciences of the United States of America, vol. 107, no. 29, pp. 12895-12900, 2010.

[83] O. Cohen, S. Kfir-Erenfeld, R. Spokoini, Y. Zilberman, E. Yefenof, and R. V. Sionov, "Nitric oxide cooperates with glucocorticoids in thymic epithelial cell-mediated apoptosis of double positive thymocytes," International Immunology, vol. 21, no. 10, pp. 1113-1123, 2009.

[84] D. Wang, N. Müller, K. G. McPherson, and H. M. Reichardt, "Glucocorticoids engage different signal transduction pathways to induce apoptosis in thymocytes and mature T cells," Journal of Immunology, vol. 176, no. 3, pp. 1695-1702, 2006.

[85] I. Kiss, H. Oskolás, R. Tóth et al., "Adenosine A2A receptormediated cell death of mouse thymocytes involves adenylate cyclase and Bim and is negatively regulated by Nur77," European Journal of Immunology, vol. 36, no. 6, pp. 1559-1571, 2006.

[86] M. Samms, D. Philp, F. Emanus, O. Osuji, M. Pezzano, and J. C. Guyden, "Lysosomal-mediated degradation of apoptotic thymocytes within thymic nurse cells," Cellular Immunology, vol. 197, no. 2, pp. 108-115, 1999.

[87] Y. C. Kim, R. Bhairavabhotla, J. Yoon et al., "Oligodeoxinucleotides stabilize Helios-expressing Foxp3+ human T regulatory cells during in vitro expansion," Blood, vol. 119, no. 12, pp. 2810-2818, 2012.

[88] T. Wakimoto, R. Tomisaka, Y. Nishikawa, H. Sato, T. Yoshino, and K. Takahashi, "Identification and characterization of human thymic cortical dendritic macrophages that may act as professional scavengers of apoptotic thymocytes," Immunobiology, vol. 213, no. 9-10, pp. 837-847, 2008.

[89] M. Samms, M. Martinez, S. Fousse, M. Pezzano, and J. C. Guyden, "Circulating macrophages as well as developing thymocytes are enclosed within thymic nurse cells," Cellular Immunology, vol. 212, no. 1, pp. 16-23, 2001.

[90] A. C. Zambon, A. Wilderman, A. Ho, and P. A. Insel, "Increased expression of the pro-apoptotic protein BIM, a mechanism for cAMP/protein kinase A, (PKA)-induced apoptosis of immature T cells," The Journal of Biological Chemistry, vol. 286, no. 38, pp. 33260-33267, 2011.

[91] N. Sakaguchi, T. Takahashi, H. Hata et al., "Altered thymic T-cell selection due to a mutation of the ZAP-70 gene causes autoimmune arthritis in mice," Nature, vol. 426, no. 6965, pp. 454-460, 2003.

[92] M. A. Wallet, R. R. Flores, Y. Wang et al., "MerTK regulates thymic selection of autoreactive T cells," Proceedings of the National Academy of Sciences of the United States of America, vol. 106, no. 12, pp. 4810-4815, 2009. 
[93] J. J. Moon, P. Dash, T. H. Oguin III et al., "Quantitative impact of thymic selection on Foxp3+ and Foxp3- subsets of selfpeptide/MHC-class II-specific CD4+ T cells," Proceedings of the National Academy of Sciences of the United States of America, vol. 108, no. 35, pp. 14602-14607, 2011.

[94] K. D. Song, S. Hwang, and C. H. Yun, "T cell receptor signaling that regulates the development of intrathymic natural regulatory T cells," Immune Network, vol. 11, no. 6, pp. 336-341, 2011.

[95] J. A. Bluestone and A. K. Abbas, "Natural versus adaptive regulatory T cells," Nature Reviews Immunology, vol. 3, no. 3, pp. 253-257, 2003.

[96] I. Kryczek, K. Wu, E. Zhao et al., "IL-17+ regulatory T Cells in the microenvironments of chronic inflammation and cancer," Journal of Immunology, vol. 186, no. 7, pp. 4388-4395, 2011.

[97] T. Dasu, J. E. Qualls, H. Tuna, C. Raman, D. A. Cohen, and S. Bondada, "CD5 plays an inhibitory role in the suppressive function of murine CD4+ CD25+ Treg cells," Immunology Letters, vol. 119, no. 1-2, pp. 103-113, 2008.

[98] R. K. Dinesh, B. J. Skaggs, A. La Cava, B. H. Hahn, and R. P. Singh, "CD8+ Tregs in lupus, autoimmunity, and beyond," Autoimmunity Reviews, vol. 9, no. 8, pp. 560-568, 2010.

[99] S. Sakaguchi, K. Wing, Y. Onishi, P. Prieto-Martin, and T. Yamaguchi, "Regulatory T cells: how do they suppress immune responses?" International Immunology, vol. 21, no. 10, pp. 1105-1111, 2009.

[100] V. Pillai, S. B. Ortega, C. K. Wang, and N. J. Karandikar, "Transient regulatory T-cells: a state attained by all activated human T-cells," Clinical Immunology, vol. 123, no. 1, pp. 18-29, 2007.

[101] M. A. Curotto de Lafaille and J. J. Lafaille, "Natural and adaptive foxp3+ regulatory $\mathrm{T}$ cells: more of the same or a division of labor?” Immunity, vol. 30, no. 5, pp. 626-635, 2009.

[102] S. Sakaguchi, N. Sakaguchi, M. Asano, M. Itoh, and M. Toda, "Immunologic self-tolerance maintained by activated $\mathrm{T}$ cells expressing IL- 2 receptor $\alpha$-chains (CD25): breakdown of a single mechanism of self- tolerance causes various autoimmune diseases," Journal of Immunology, vol. 155, no. 3, pp. 1151-1164, 1995.

[103] D. Getnet, J. F. Grosso, M. V. Goldberg et al., "A role for the transcription factor Helios in human CD4+CD25+ regulatory T cells," Molecular Immunology, vol. 47, no. 7-8, pp. 1595-1600, 2010.

[104] D. Haribhai, J. B. Williams, S. Jia et al., "A requisite role for induced regulatory $\mathrm{T}$ cells in tolerance based on expanding antigen receptor diversity," Immunity, vol. 35, no. 1, pp. 109-122, 2011.

[105] C. S. Hsieh, H. M. Lee, and C. W. Lio, "Selection of regulatory T cells in the thymus," Nature Reviews Immunology, vol. 12, no. 3, pp. 157-167, 2012.

[106] C. Veldman, A. Nagel, and M. Hertl, “Type I regulatory T cells in autoimmunity and inflammatory diseases," International Archives of Allergy and Immunology, vol. 140, no. 2, pp. 174-183, 2006.

[107] A. Coutinho, I. Caramalho, E. Seixas, and J. Demengeot, "Thymic commitment of regulatory $\mathrm{T}$ cells is a pathway of TCR-dependent selection that isolates repertoires undergoing positive or negative selection," Current Topics in Microbiology and Immunology, vol. 293, pp. 43-71, 2005.

[108] X. Zhou, S. Bailey-Bucktrout, L. T. Jeker, and J. A. Bluestone, "Plasticity of CD4+ FoxP3+ T cells," Current Opinion in Immunology, vol. 21, no. 3, pp. 281-285, 2009.
[109] G. Y. Chen, C. Chen, L. Wang, X. Chang, P. Zheng, and Y. Liu, "Cutting edge: broad expression of the FoxP3 locus in epithelial cells: a caution against early interpretation of fatal inflammatory diseases following in vivo depletion of FoxP3-expressing cells," Journal of Immunology, vol. 180, no. 8, pp. 5163-5166, 2008.

[110] A. Lesiak, P. Smolewski, D. Sobolewska-Sztychny, A. SysaJedrzejowska, and J. Narbutt, "The role of T regulatory cells and Toll-like receptors 2 and 4 in atopic dermatitis," Scandinavian Journal of Immunology, vol. 76, no. 4, pp. 405-410, 2012.

[111] J. Yang, J. X. Zhang, H. Wang, G. L. Wang, Q. G. Hu, and Q. C. Zheng, "Hepatocellular carcinoma and macrophage interaction induced tumor immunosuppression via Treg requires TLR4 signaling," World Journal of Gastroenterology, vol. 18, no. 23, pp. 2938-2947, 2012.

[112] S. Sakaguchi, T. Yamaguchi, T. Nomura, and M. Ono, "Regulatory T cells and immune tolerance," Cell, vol. 133, no. 5, pp. 775-787, 2008.

[113] A. Suto, H. Nakajima, K. Ikeda et al., "CD4+CD25+ T-cell development is regulated by at least 2 distinct mechanisms," Blood, vol. 99, no. 2, pp. 555-560, 2002.

[114] J. D. Fontenot, J. L. Dooley, A. G. Farr, and A. Y. Rudensky, "Developmental regulation of Foxp3 expression during ontogeny," Journal of Experimental Medicine, vol. 202, no. 7, pp. 901-906, 2005.

[115] N. Komatsu, M. E. Mariotti-Ferrandiz, Y. Wang, B. Malissen, H. Waldmann, and S. Hori, "Heterogeneity of natural Foxp3+ T cells: a committed regulatory T-cell lineage and an uncommitted minor population retaining plasticity," Proceedings of the National Academy of Sciences of the United States of America, vol. 106, no. 6, pp. 1903-1908, 2009.

[116] K. Wing and S. Sakaguchi, "Regulatory T cells exert checks and balances on self tolerance and autoimmunity," Nature Immunology, vol. 11, no. 1, pp. 7-13, 2010.

[117] N. Watanabe, Y. H. Wang, H. K. Lee et al., "Hassall's corpuscles instruct dendritic cells to induce CD $4+\mathrm{CD} 25+$ regulatory T cells in human thymus," Nature, vol. 436, no. 7054, pp. 1181-1185, 2005.

[118] M. Zen, M. Canova, C. Campana et al., "The kaleidoscope of glucorticoid effects on immune system," Autoimmunity Reviews, vol. 10, no. 6, pp. 305-310, 2011.

[119] J. Ye, X. Huang, E. C. Hsueh et al., "Human regulatory T cells induce T lymphocyte senescence," Blood, vol. 120, no. 10, pp. 2021-2031, 2012.

[120] J. X. Zhao, Y. Y. Zeng, and Y. Liu, "Fetal alloantigen is responsible for the expansion of the CD4+CD25+ regulatory T cell pool during pregnancy," Journal of Reproductive Immunology, vol. 75, no. 2, pp. 71-81, 2007.

[121] B. Blankenhaus, U. Klemm, M. L. Eschbach et al., "Strongyloides ratti infection induces expansion of foxp3+ regulatory $\mathrm{T}$ cells that interfere with immune response and parasite clearance in BALB/c Mice," Journal of Immunology, vol. 186, no. 7, pp. 4295-4305, 2011.

[122] R. D’Elia, J. M. Behnke, J. E. Bradley, and K. J. Else, “Regulatory $\mathrm{T}$ cells: a role in the control of helminth-driven intestinal pathology and worm survival," Journal of Immunology, vol. 182, no. 4, pp. 2340-2348, 2009.

[123] C. A. Zago, K. R. Bortoluci, L. R. Sardihna et al., "Anti-IL-12 treatment impairs the expansión of $\mathrm{T}_{\text {req }}$ cell population during acute malaria and enhances the Th1 cell response at the chronic disease," PLoS One, vol. 7, no. 1, Article ID e29894, 2012.

[124] M. P. Hübner, J. T. Stocker, and E. Mitre, "Inhibition of type 1 diabetes in filaria-infected non-obese diabetic mice is 
associated with a T helper type 2 shift and induction of FoxP3+ regulatory T cells," Immunology, vol. 127, no. 4, pp. 512-522, 2009.

[125] E. Roat, N. Prada, E. Lugli et al., "Homeostatic cytokines and expansion of regulatory $\mathrm{T}$ cells accompany thymic impairment in children with Down syndrome," Rejuvenation Research, vol. 11, no. 3, pp. 573-583, 2008.

[126] S. E. Allan, R. Broady, S. Gregori et al., "CD4+ T-regulatory cells: toward therapy for human diseases," Immunological Reviews, vol. 223, no. 1, pp. 391-421, 2008.

[127] K. Monte, C. Wilson, and F. F. Shih, "Increased number and function of FoxP3 regulatory $\mathrm{T}$ cells during experimental arthritis," Arthritis and Rheumatism, vol. 58, no. 12, pp. 3730-3741, 2008.

[128] A. Alunno, E. Bartoloni, O. Bistoni et al., "Balance between regulatory $\mathrm{T}$ and Th17 cells in systemic lupus erythematosus: the old and the new," Clinical and Developmental Immunology, vol. 2012, Article ID 823085, 5 pages, 2012.

[129] K. Lahl, C. Loddenkemper, C. Drouin et al., "Selective depletion of Foxp3+ regulatory T cells induces a scurfy-like disease," Journal of Experimental Medicine, vol. 204, no. 1, pp. 57-63, 2007.

[130] P. Alard, J. N. Manirarora, S. A. Parnell, J. L. Hudkins, S. L. Clark, and M. M. Kosiewicz, "Deficiency in NOD antigen-presenting cell function may be responsible for suboptimal CD4+CD25+ T-cell-mediated regulation and type 1 diabetes development in NOD mice," Diabetes, vol. 55, no. 7, pp. 2098-2105, 2006.

[131] Y. V. Tan, C. Abad, R. Lopez et al., "Pituitary adenylyl cyclase-activating polypeptide is an intrinsic regulator of Treg abundance and protects against experimental autoimmune encephalomyelitis," Proceedings of the National Academy of Sciences of the United States of America, vol. 106, no. 6, pp. 2012-2017, 2009.

[132] S. Deng, Y. Xi, H. Wang et al., "Regulatory effect of vasoactive intestinal peptide on the balance of Treg and Th17 in collageninduced arthritis," Cellular Immunology, vol. 265, no. 2, pp. 105-110, 2010.

[133] D. W. Wang, R. B. Zhou, Y. M. Yao et al., "Stimulation of $\alpha 7$ nicotinic acetylcholine receptor by nicotine increases suppressive capacity of naturally occurring CD4+CD25 + regulatory $\mathrm{T}$ cells in mice in vitro," Journal of Pharmacology and Experimental Therapeutics, vol. 335, no. 3, pp. 553-561, 2010.

[134] J. Mjösberg, J. Svensson, E. Johansson et al., "Systemic reduction of functionally suppressive CD4dimCD25 highFoxp3+ tregs in human second trimester pregnancy is induced by progesterone and $17 \beta$-estradiol," Journal of Immunology, vol. 183, no. 1, pp. 759-769, 2009.

[135] C. Wang, B. Dehghani, Y. Li, L. J. Kaler, A. A. Vandenbark, and H. Offner, "Oestrogen modulates experimental autoimmune encephalomyelitis and interleukin-17 production via programmed death 1," Immunology, vol. 126, no. 3, pp. 329-335, 2009.

[136] A. Li, X. Liu, B. Duan, and J. Ma, "Thymic nurse cells support CD4-CD8+ thymocytes to differentiate into CD4+CD8+ cells," Cellular \& Molecular Immunology, vol. 2, no. 4, pp. 301-305, 2005.

[137] K. Sakabe, I. Kawashima, R. Urano, K. Seiki, and T. Itoh, "Effects of sex steroids on the proliferation of thymic epithelial cells in a culture model: a role of protein kinase C," Immunology and Cell Biology, vol. 72, no. 3, pp. 193-199, 1994.
[138] W. Savino, D. M. S. Villa-Verde, L. A. Alves, and M. Dardenne, "Neuroendocrine control of the thymus," Annals of the New York Academy of Sciences, vol. 840, pp. 470-479, 1998.

[139] M. Levite, "Neurotransmitters activate T-cells and elicit crucial functions via neurotransmitter receptors," Current Opinion in Pharmacology, vol. 8, no. 4, pp. 460-471, 2008.

[140] I. J. Elenkov, R. L. Wilder, G. P. Chrousos, and E. S. Vizi, "The sympathetic nerve-an integrative interface between two supersystems: the brain and the immune system," Pharmacological Reviews, vol. 52, no. 4, pp. 595-638, 2000.

[141] D. M. Nance and V. M. Sanders, "Autonomic innervation and regulation of the immune system (1987-2007)," Brain, Behavior, and Immunity, vol. 21, no. 6, pp. 736-745, 2007.

[142] D. L. Felten, S. Y. Felten, S. L. Carlson, J. A. Olschowka, and S. Livnat, "Noradrenergic and peptidergic innervation of lymphoid tissue," Journal of Immunology, vol. 135, no. 2, supplement, pp. 755s-765s, 1985.

[143] M. D. Kendall and A. A. Al-Shawaf, "Innervation of the rat thymus gland," Brain, Behavior, and Immunity, vol. 5, no. 1, pp. 9-28, 1991.

[144] S. Bhowmick, A. Singh, R. A. Flavell, R. B. Clark, J. O’Rourke, and R. E. Cone, "The sympathetic nervous system modulates $\mathrm{CD} 4+\mathrm{FoxP} 3+$ regulatory $\mathrm{T}$ cells via a TGF- $\beta$-dependent mechanism," Journal of Leukocyte Biology, vol. 86, no. 6, pp. 1275-1283, 2009.

[145] E. S. Vizi, E. Orsó, O. N. Osipenko, G. Haskó, and I. J. Elenkov, "Neurochemical, electrophysiological and immunocytochemical evidence for a noradrenergic link between the sympathetic nervous system and thymocytes," Neuroscience, vol. 68, no. 4, pp. 1263-1276, 1995.

[146] B. Kurz, J. Feindt, B. von Gaudecker, A. Kranz, H. Loppnow, and R. Mentlein, " $\beta$-Adrenoceptor-mediated effects in rat cultured thymic epithelial cells," British Journal of Pharmacology, vol. 120, no. 8, pp. 1401-1408, 1997.

[147] F. Mignini, M. Sabbatini, V. D’Andrea, and C. Cavallotti, "Intrinsic innervation and dopaminergic markers after experimental denervation in rat thymus," European Journal of Histochemistry, vol. 54, no. 2, article e17, 2010.

[148] X. Li, S. Taylor, B. Zegarelli, S. Shen, J. O'Rourke, and R. E. Cone, "The induction of splenic suppressor T cells through an immune-privileged site requires an intact sympathetic nervous system," Journal of Neuroimmunology, vol. 153, no. 1-2, pp. 40-49, 2004.

[149] G. M. Head, R. Mentlein, B. von Patay, J. E. G. Downing, and M. D. Kendall, "Neuropeptides exert direct effects on rat thymic epithelial cells in culture," Developmental Immunology, vol. 6, no. 1-2, pp. 95-104, 1998.

[150] O. K. Nihei, A. C. Campos de Carvalho, D. C. Spray, W. Savino, and L. A. Alves, "A novel form of cellular communication among thymic epithelial cells: intercellular calcium wave propagation," American Journal of Physiology, vol. 285, no. 5, pp. C1304-C1313, 2003.

[151] I. Rinner, A. Globerson, K. Kawashima, W. Korsatko, and K. Schauenstein, "A possible role for acetylcholine in the dialogue between thymocytes and thymic stroma," NeuroImmunomodulation, vol. 6, no. 1-2, pp. 51-55, 1999.

[152] N. A. Forward, S. J. Furlong, Y. Yang, T. J. Lin, and D. W. Hoskin, "Mast cells down-regulate CD4+CD25+ T regulatory cell suppressor function via histamine $\mathrm{H} 1$ receptor interaction," Journal of Immunology, vol. 183, no. 5, pp. 3014-3022, 2009.

[153] N. R. Hall, A. Suria, and A. L. Goldstein, "Elevated levels of gamma amino butyric acid (GABA) in the thymus gland during 
the immune response," Lymphokine Research, vol. 4, no. 4, pp. 339-341, 1985.

[154] K. Maemura, Y. Yanagawa, K. Obata et al., "Antigen-presenting cells expressing glutamate decarboxylase 67 were identified as epithelial cells in glutamate decarboxylase 67-GFP knock-in mouse thymus," Tissue Antigens, vol. 67, no. 3, pp. 198-206, 2006.

[155] D. Cavallotti, M. Artico, C. Cavallotti, S. De Santis, and F. T. Leali, "Interleukin $1 \beta$ and GABA-transaminase activity in rat thymus," International Journal of Immunopharmacology, vol. 22, no. 9, pp. 719-728, 2000.

[156] M. G. Reyes-García, F. Hernández-Hernández, B. HernándezTéllez, and F. García-Tamayo, "GABA (A) receptor subunits RNA expression in mice peritoneal macrophages modulate their IL-6/IL-12 production," Journal of Neuroimmunology, vol. 188, no. 1-2, pp. 64-68, 2007.

[157] I. N. Tyurenkov, M. A. Samotrueva, and A. N. Ovcharova, "Effect of baclofen on the characteristics of cellular immune response," Eksperimental'naya i Klinicheskaya Farmakologiya, vol. 71, no. 3, pp. 43-45, 2008.

[158] J. Tian, N. H. Dang, and L. Kaufman, "Combined antigen-based therapy with GABA treatment synergistically prolongs survival of transplanted b-cells in diabetic NOD mice," PLOsOne, vol. 6, no. 9, Article ID e25337, 2011.

[159] J. Tian, H. N. Dang, J. Yong et al., "Oral treatment with g-aminobutyric acid improves glucose tolerance and insulin sensitivity by inhibiting inflammation in high fat diet-fed mice," PLoS One, vol. 6, no. 9, Article ID e25338, 2011.

[160] K. M. Grebe, "Regulation of the regulator: sympathetic nervous system control of regulatory T cells," Journal of Leukocyte Biology, vol. 86, no. 6, pp. 1269-1270, 2009. 

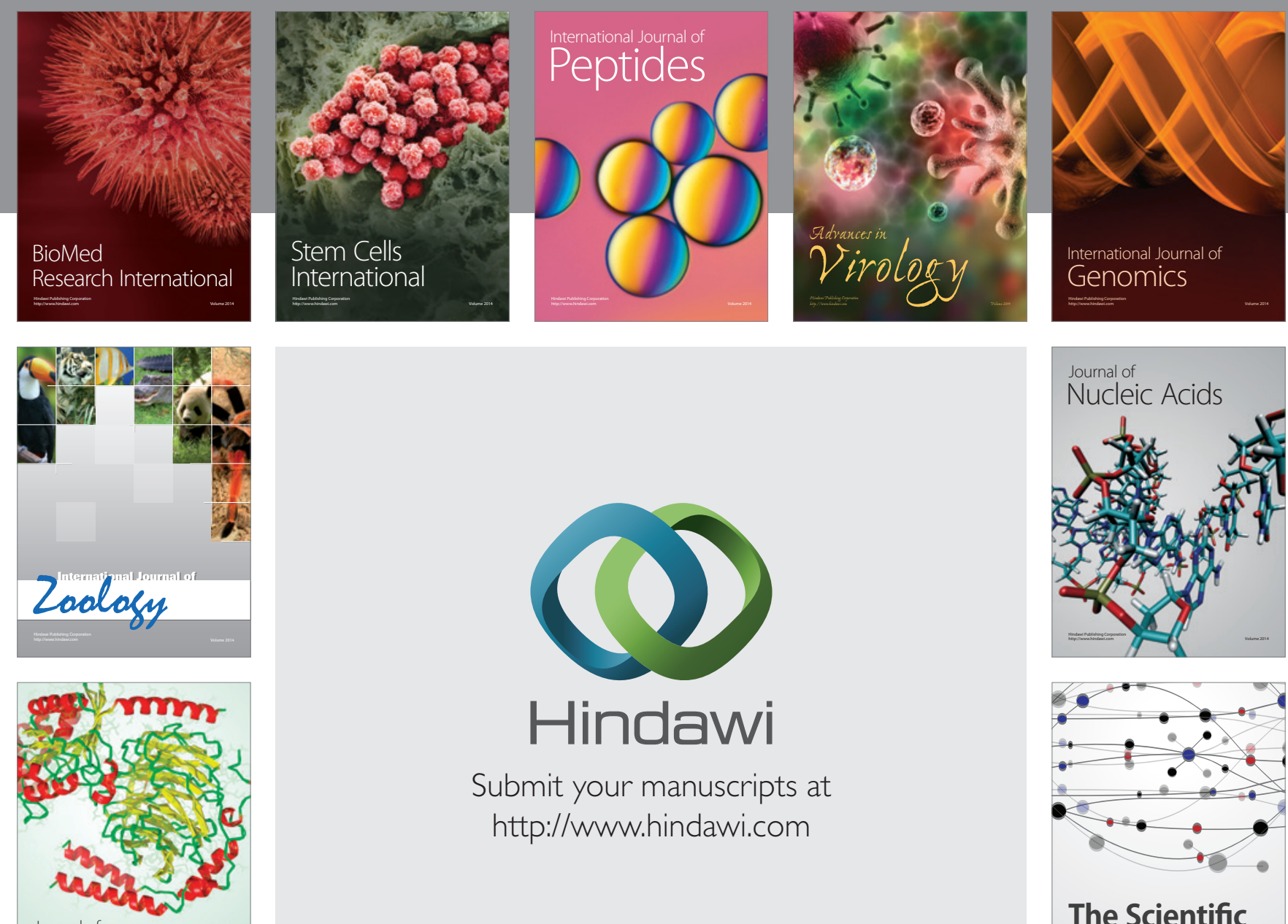

Submit your manuscripts at

http://www.hindawi.com

Journal of
Signal Transduction
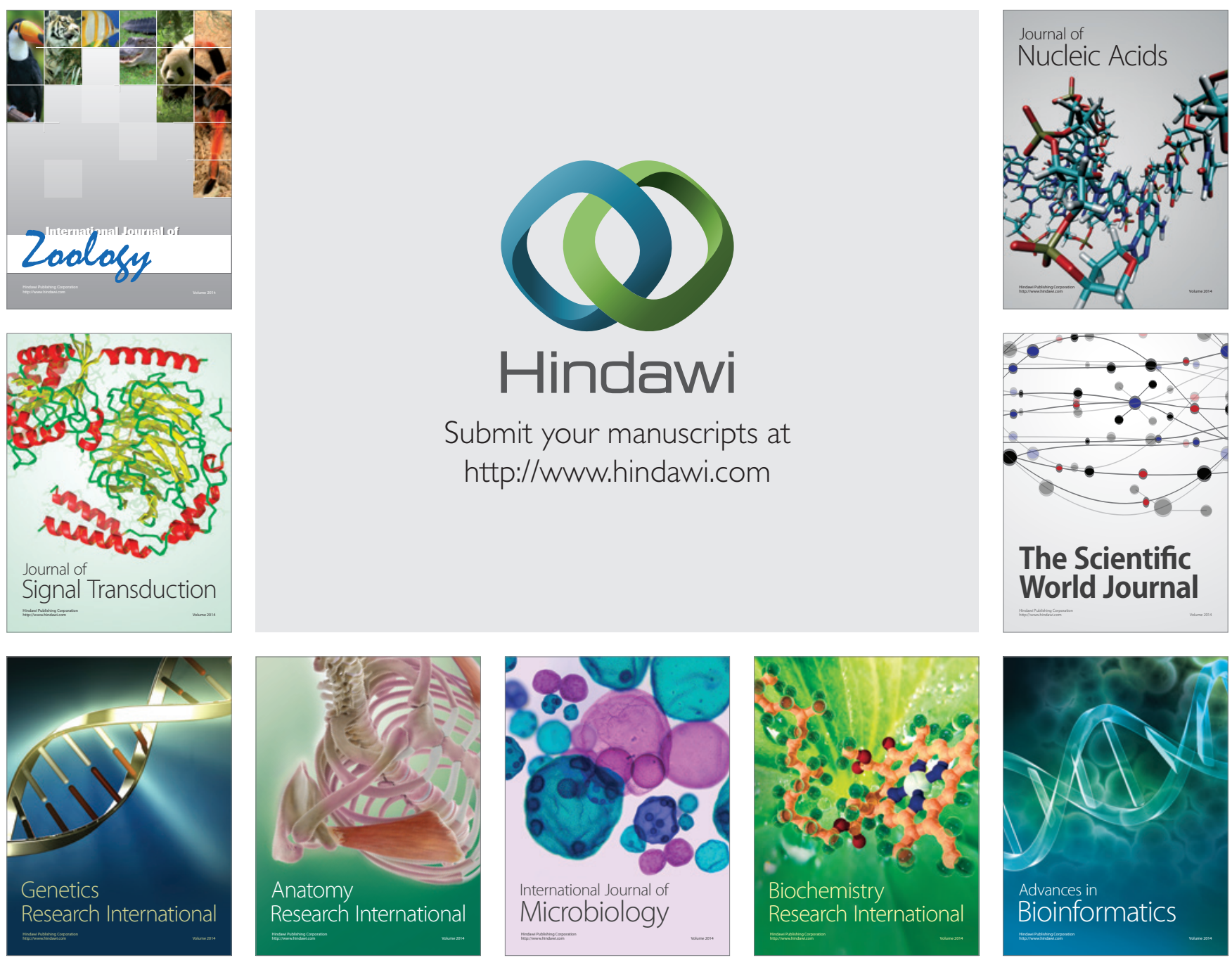

The Scientific World Journal
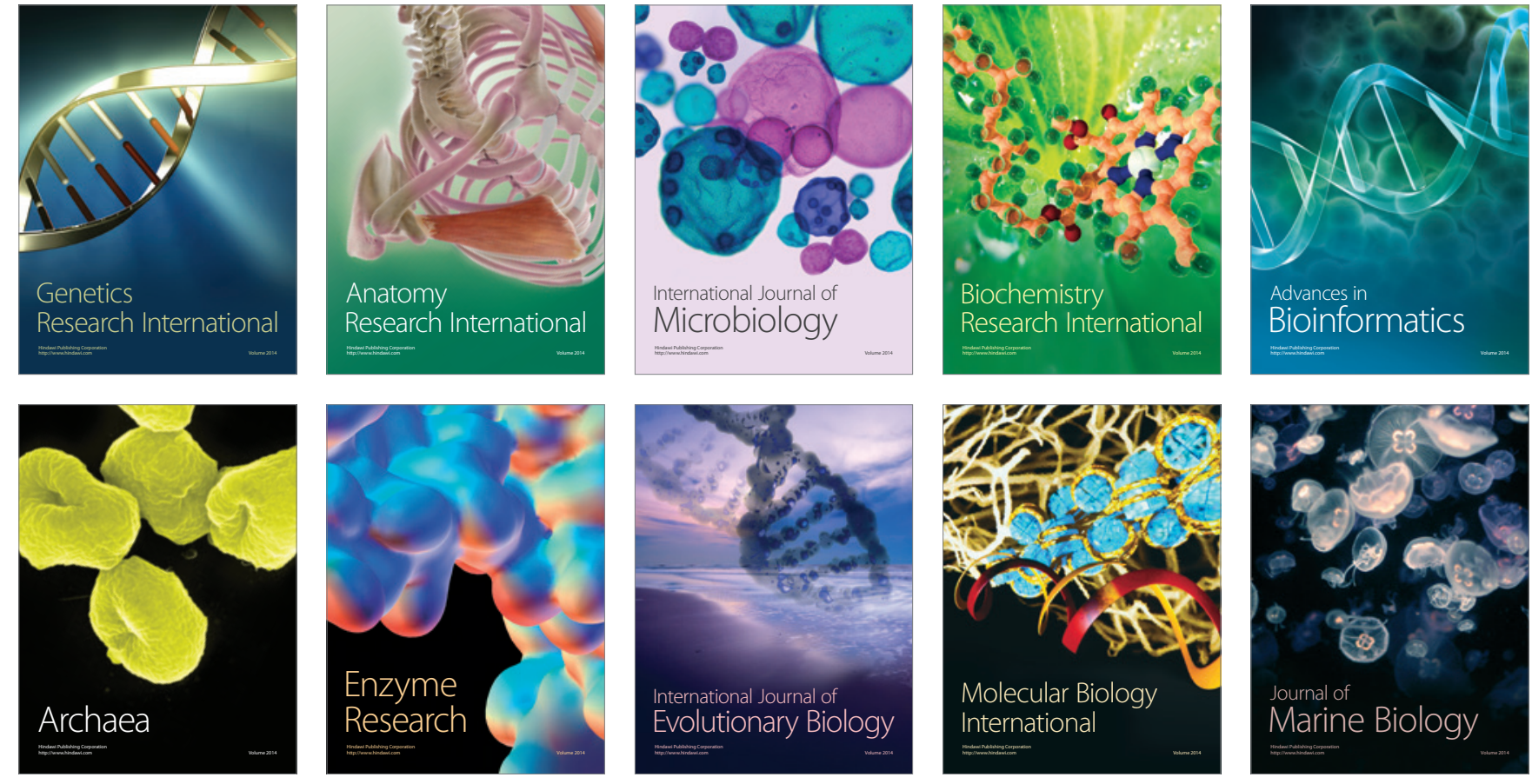